\title{
Patients' preferences for antiretroviral therapy service provision: a systematic review
}

\author{
Yihalem Abebe Belay ${ }^{1,2^{*}}$, Mezgebu Yitayal ${ }^{2}$, Asmamaw Atnafu² and Fitalew Agimass Taye ${ }^{3}$
}

\begin{abstract}
Background: Achieving global targets of adherence to treatment, retention in care, and treatment success remains a challenge. Health system investment to make antiretroviral therapy services more responsive to patients' needs and values could address these impediments. Appropriate resource allocation to implement differentiated HIV treatment services demands research evidence. This study aimed to provide an overview of the patients' preferences for antiretroviral therapy service delivery features.

Methods: Electronic databases (PubMed, Web of Science, Embase, and CINAHL) and search engines (Google and Google Scholar) were searched. This review has followed a convergent segregated approach to synthesis and integration. Data from the included studies were systematically extracted, tabulated, and summarised in a narrative review. Studies that analysed preferences for antiretroviral therapy regardless of the method used and published in the English language in any year across the world and HIV positive clients who were 15 years and above on 4th February 2021 were included for this review. The quality of the included studies was assessed using the mixed methods appraisal tool. A thematic synthesis of the data from the findings section of the main body of the qualitative study was undertaken. ATLAS.ti software version 7 was used for qualitative synthesis.

Results: From the 1054 retrieved studies, only 23 studies (16 quantitative, three qualitative, and four mixed-methods) fulfilled the inclusion criteria. The median number of attributes used in all included quantitative studies was 6 (Inter Quartile Range 3). In this review, no study has fulfilled the respective criteria in the methodological quality assessment. In the quantitative synthesis, the majority of participants more valued the outcome, whereas, in the qualitative synthesis, participants preferred more the structure aspect of antiretroviral therapy service. The thematic analysis produced 17 themes, of which ten themes were related to structure, three to process, and four to outcome dimension of Donabedian's quality of care model. The findings from individual quantitative and qualitative syntheses complement each other.
\end{abstract}

Conclusions: In this review, participants' value for antiretroviral therapy service characteristics varied across included studies. Priorities and values of people living with HIV should be incorporated in the policy, practice, research, and development efforts to improve the quality of antiretroviral therapy service hence avoid poor patient outcomes.

Keywords: Preferences, Antiretroviral therapy, Mixed-methods, Systematic review

*Correspondence: yih2000ho@gmail.com

1 Department of Public Health, College of Health Sciences, Debre Markos University, Debre Markos, Ethiopia

Full list of author information is available at the end of the article permits use, sharing, adaptation, distribution and reproduction in any medium or format, as long as you give appropriate credit to the original author(s) and the source, provide a link to the Creative Commons licence, and indicate if changes were made. The images or other third party material in this article are included in the article's Creative Commons licence, unless indicated otherwise in a credit line to the material. If material is not included in the article's Creative Commons licence and your intended use is not permitted by statutory regulation or exceeds the permitted use, you will need to obtain permission directly from the copyright holder. To view a copy of this licence, visit http://creativecommons.org/licenses/by/4.0/. The Creative Commons Public Domain Dedication waiver (http://creativeco mmons.org/publicdomain/zero/1.0/) applies to the data made available in this article, unless otherwise stated in a credit line to the data. 


\section{Background}

Human Immunodeficiency Virus (HIV) infection continues to be a major public health issue throughout the world. Since the start of the pandemic, 75.7 million people have become infected, and 32.7 million people have died from AIDS-related illnesses. Globally by the end of 2019, 38 million people were living with HIV, 1.7 million people were newly infected, and 690,000 people died from AIDS-related illnesses [1, 2]. Over two-thirds (25.7 million) of all people living with HIV reside in Africa [2].

The Sustainable Development Goal (SDG) 3 includes the promise made by the Member States to achieve the end of AIDS by 2030 [3]. To address this issue, the UNAIDS put the target to have $90 \%$ of all people living with HIV (PLHIV) will know their HIV status, $90 \%$ of those diagnosed with HIV infection will receive a sustained combination of antiretroviral therapy (ART), and $90 \%$ of all people receiving ART will have suppressed viral load by 2020. A subsequent 95-95-95 goal is set for 2030 [4]. Moreover, the World Health Organization (WHO) recommends ART for all people diagnosed with HIV (test and treat approach) [5]. Despite such global efforts, ensuring adherence to HIV treatment, retention in care, and treatment success are challenges to low and middle-income countries (LMICs), which require commitment from the patient and the health care team and a productive patient-provider relationship [2].

As the availability of ART for the treatment of HIV/ AIDS has increased in resource-limited settings, there has been a move to develop and implement alternative treatment delivery models (also referred to as "differentiated models of service delivery" or DSD) in high HIV prevalence countries to meet the global targets for HIV treatment while maintaining the quality of care [6]. Differentiated ART delivery is a component of DSD. It aims to improve retention and viral suppression by optimizing models of drug and care delivery. Differentiated ART delivery focuses specifically on clients who are on treatment [7].

Differentiated models of ART service delivery typically differ across one or more of the service characteristics (provider, location, frequency, and intensity of care) and aim to provide a more patient-centered service [8, 9]. Four DSD models that focus on stable ART clients are recently identified $[10,11]$. They include (1) healthcare worker (HCW) managed groups, (2) facility-based individual models, (3) client managed groups, and (4) outof-facility individual models. In HCW managed groups, clients receive their ART refills in a group either from a health professional or a lay healthcare staff member. In these models, clients meet in and/or outside of the health care facilities. In facility-based individual models, clients bypass any clinical staff or adherence support and proceed directly to receive their medication. Appointment spacing and the "fast-track" ART refill model are an example of these models. In client-managed group models, clients receive their ART refills in a group in which clients meet outside of health care facilities and manage and run the refills themselves. For out-of-facility individual models, ART refills and, in some cases, clinical consultations are provided to individuals outside of health care facilities; for example, community pharmacies, outreach models, and home delivery [7].

WHO has defined stable individuals as "those who have received ART for at least 1 year and have no adverse drug reactions that require regular monitoring, have no current illnesses or pregnancy, have not been currently breastfeeding, have a good understanding of lifelong adherence and evidence of treatment success (i.e., two consecutive viral load measurements below 1000 copies $/ \mathrm{mL}$ ). However, in the absence of viral load monitoring and rising CD4 cell counts or CD4 counts $>200$ cells/ $\mathrm{mm}^{3}$, an objective adherence measure can be used to indicate treatment success" [5].

Implementation and strategy prioritization of HIV programs have been difficult in most resource-limited settings [12]. Research and development are required in this regard to bring more innovative ART delivery models. Through the understanding of the aspects of antiretroviral therapy that are of particular importance to PLHIV, it may be possible to develop new models of care that maintain these high levels of adherence, engagement with care, and treatment success. Nowadays, patient preferences studies are increasingly used to inform clinical and policy decision-making in health care in the context of resource constraints [13]. Several quantitative and qualitative studies assessing patients' preferences for ART service have been published, although a little attempt has been made to synthesize the research findings. Previous reviews lacked particular focus and in-depth investigation of ART service provision. Most of the systematic reviews were conducted on the general HIV care aspects (prevention, counseling and testing, service delivery, and ART) $[14,15]$, included only discrete choice experimentbased studies on HIV treatment service ignoring other designs [16], and focused on HIV care in high-income countries which are not highly affected by the HIV pandemic [14].

This study was a mixed systematic review to contribute to a better and comprehensive understanding of patients' preferences for ART service provision. It was designed to elaborate on preferences of HIV-positive clients aged 15 years and above, with the goal of aiding policymakers, program managers, and practitioners in Ethiopia and other settings as they expand ART services. 


\section{Methods}

\section{Protocol registration}

The Preferred Reporting Items for Systematic Reviews and Meta-analyses (PRISMA) guideline [17] was used to report the result of this mixed-method systematic review. Protocol for this review was registered in the International Prospective Register of Systematic Reviews (PROSPERO) database on ID no: CRD42020212064.

\section{Databases and search strategy}

The literature search was undertaken from inception to 4th February 2021 using PubMed, Web of Science, Embase, and CINAHL databases. In addition, articles were selected using manual search via Google and Google Scholar search engines by combining the search terms used for databases accessed for primary data sources. The SPIDER question framework was employed, and searches used free text and MeSH terms relating to the following: (i) sample (patients); (ii) the phenomena of interest (antiretroviral therapy, antiretroviral treatment, human immunodeficiency virus therapy, HIV treatment, HIV medication, HIV/AIDS therapy, HIV/AIDS treatment, differentiated antiretroviral therapy); (iii) evaluation (preference, patient preference, stated preference, stated choice); and (iv) research type (qualitative, mixed-methods, and quantitative such as conjoint analysis, discrete choice experiment, ranking study, swing weighting study, analytical hierarchy process, best-worst scaling, adaptive conjoint analysis) for all available studies. Besides, the reference lists of included articles were searched manually. The search string was developed using "AND" and "OR" Boolean Operators. The complete search strategy based on keywords is available in Additional file 1.

\section{Study eligibility and selection}

The eligible studies were selected based on the following criteria: (1) analysis of preferences for ART regardless of the method used, (2) being written in English, and (3) sampling of HIV-positive individuals aged 15 years and above. Studies conducted on HIV services other than ART (prevention, counseling and testing, and service delivery); review articles and studies conducted among children, adolescents, pregnant and breastfeeding women and key populations (people who inject drugs, men having sex with men, transgender persons, sex workers, and prisoners) due to special criteria for defining clinically stable clients and key considerations for social and legal issues in accessing ART services were excluded from this review.

All retrieved studies were exported to Endnote version 9 (Thomson Reuters, London) reference manager, and duplicates were carefully removed. Two investigators
(YAB and FAT) independently screened thorough review from the title, abstract, and full text of each study. Any disagreements that arose between the reviewers were resolved through discussion.

\section{Assessment of methodological quality}

Two independent reviewers (YAB and MY) assessed the quality of the studies. The Mixed Methods Appraisal Tool (MMAT) [18] was used to evaluate the quality of included studies. This tool includes specific criteria for mixed methods studies, as well as for qualitative and quantitative studies. The tool discourages the use of a scoring system and instead advises to put a detailed presentation of the ratings to provide a better explanation of the quality of the included studies. Any disagreements that arose between the reviewers were resolved through discussion.

Due to the complexities associated with recommendations being derived from both quantitative and qualitative evidence, an assessment of the certainty of the evidence using either the Grading of Recommendations, Assessment, Development and Evaluations (GRADE) or ConQual approach is currently not recommended for JBI Mixed methods research following the segregated approach and not yet assessed in this review [19].

\section{Data extraction}

The data from primary level studies conducted using qualitative, quantitative, and mixed methods were extracted using JBI data extraction tools in the form of customized Microsoft Excel [20]. Two independent reviewers (YAB and $\mathrm{AA}$ ) extracted the data and crosschecked it to ensure consistency. Discrepancies were solved by discussion and repeating the procedure. The reviewer (YAB) contacted the corresponding author(s) for further information whenever pertinent data was missed from the included studies. Descriptive data were sorted from the studies focused on authors, study aim, year of publication, country, study region, study type, sample size, method of sample recruitment, method of data collection, and data analysis (Additional file 2).

For quantitative studies (and the quantitative component of mixed methods studies), the extracted data included specific details about the method of preference elicitation, attributes (levels), number of attributes, dimension of attributes, and importance of attributes. For qualitative studies (and the qualitative component of mixed methods studies), extracted data included specific details about the themes, key concepts, and relevant quotes appropriate to the review question. 


\section{Data synthesis and integration}

This review followed a convergent segregated approach to synthesis and integration, according to the JBI methodology for mixed-methods systematic review [19]. It involved a separate quantitative and qualitative synthesis followed by integration of the resultant quantitative and qualitative evidence. The quantitative data were examined and found to be inappropriate for a meta-analysis due to the occurrence of high heterogeneity in the study designs and results, i.e., different methods to assess preferences, differences in the choice and the definition of attributes and levels, and different ways of reporting results. A thematic synthesis of the qualitative studies was undertaken following the recommendation of Thomas and Harden [21]. ATLAS.ti software version 7 was used for qualitative data synthesis. Both quantitative and qualitative findings were presented in narrative form, including tables and figures. A narrative summary was used for the final integration of the results of the quantitative and qualitative evidence.

In this systematic review, we considered a mixed-methods type of research as studies reported using either one or more qualitative data collection methods (in-depth interviews, focus group discussions, etc.) and one of the stated preference survey methods in the same published study with clear and sufficient reported methods and findings.

In this review, we divided the identified attributes into three dimensions: structure, process, and outcome. These dimensions were based on Donabedian's model for health care quality and were appropriate to group the wide range of ART service attributes and to have a closer look at what dimensions of ART were most important for the respondents while choosing ART service delivery. The dimension "structure" refers to objective parameters such as material resources, personnel resources and organizational structure. The "Process" dimension includes all activities taking place while giving and receiving ART. The dimension "outcome" denotes the effect of ART service on the health status of patients [22]. Similarly, the impact of each attribute on patient preference regarding ART in each included study was shown by ranking and/or rating the preference (utility) values; and relative importance score, mean, or odds ratio was used depending on the reported data. The relative importance, expressed as a percentage of each of the attributes in influencing treatment decisions, was calculated for each participant by dividing the range of each attribute (utility of highest level minus utility of lowest level) by the sum of the ranges of all attributes, and multiplying it by 100 [23-25]. If a study reported the utility coefficients in a continuous scale of measurement, then the coefficients for discrete levels of each attribute were calculated in reference to a baseline category with the lowest utility value in the same attribute. In the case of the odds ratio reported in a study, the relative impact of each attribute was computed by dividing the highest odds ratio value by the lowest odds ratio value [16]. However, for studies other than discrete choice experiments (rating, ranking, or best-worst scaling studies) included in this review, the reported rankings in the form of mean, relative importance score, or graphical presentation were directly taken.

\section{Results \\ Study inclusion}

The search strategy resulted in 1004 records through $($ PubMed $=456$, Web of Science $=186$, Embase $=311$ and CINAHL $=51)$ databases. In addition, 50 studies were accessed manually using Google and Google Scholar search engines. From these, 422 duplicated records were excluded, and from articles screened using their titles and abstracts, 598 were excluded. Therefore, 34 articles were assessed for eligibility. From these, 11 articles were excluded: three were abstracts without full text [26-28], three were review articles focusing on general HIV services [14-16], one study assessed HIV infected pregnant women [29], one study was repeated publication [30], one primary study focused on general HIV service [31], one study assessed General practitioner or HIV clinic appointment [32], and one study assessed medical and psychosocial support [33]. Finally, 23 studies were included in the review. Figure 1 has shown the study selection process.

\section{Methodological quality of included studies}

The methodological quality of included studies varied. All studies presented clear research questions and collected data to address the questions. All the qualitative studies used adequate data collection methods to address the research question, reported the interpretation of results sufficiently substantiated by data, reported the findings adequately derived from the data (for example, the quotes provided to justify the themes were adequate), and provided coherence between qualitative data sources, collection, analysis, and interpretation. About one-fifth of the quantitative studies had samples that accurately represented the target population. Nearly two-thirds of studies had pre-tested questionnaires before data collection. One-fifth of the quantitative studies had reported a non-response rate indicating a low risk of non-response bias. Most quantitative studies used appropriate statistical analysis to answer the research questions. All mixed methods studies reported an adequate rationale for using a mixed-methods design to address the research question. None of the mixed methods had the different components of the study adhere to the quality criteria of each 


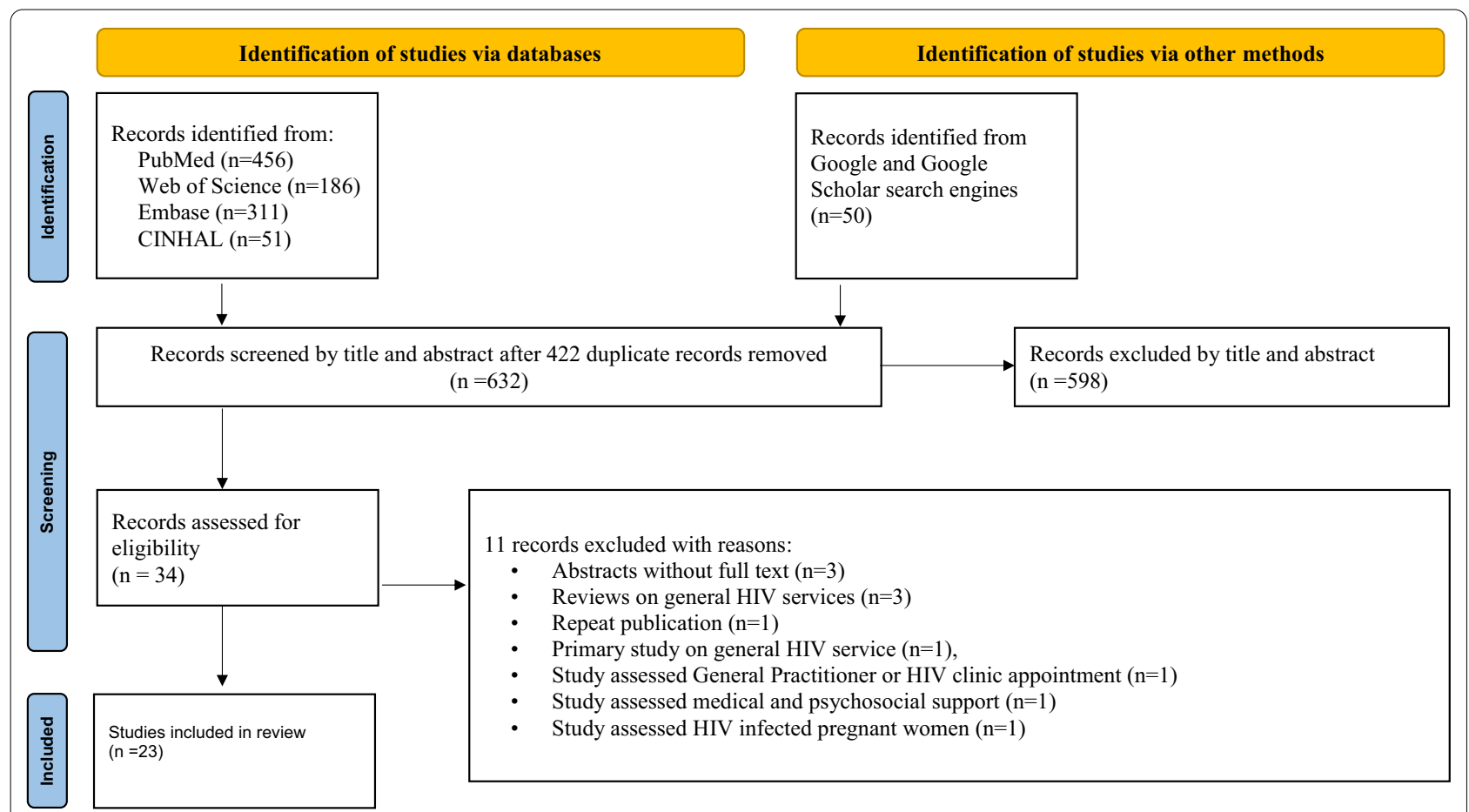

Fig. 1 Flow diagram of the included studies for the mixed-methods systematic review of patient preferences for aspects of antiretroviral therapy

tradition of the methods involved. The integration of both qualitative and quantitative evidence was effective, and results were well interpreted, and there was no divergence of the qualitative and quantitative findings. Overall, no study fulfilled the respective quality criteria. However, in this systematic review, no study was excluded owing to its methodological quality since we were interested in synthesizing all features of ART provision that have been identified as being relevant to PLHIV. The quality assessment matrix is presented in Additional file 3.

\section{Characteristics of included studies}

Our data comprised of seven studies from the African region [34-40], 10 in the Americas [23, 41-49], five in Europe [50-54], and one in both the Americas and Europe (USA and Germany) [55]. Sixteen studies were quantitative [23, 34, 36, 38, 40, 41, 43, 44, 46-48, 51$55]$ and three were qualitative [35, 39, 42]. Four articles reported both qualitative and quantitative findings [37, $45,49,50]$. The studies were published between 2002 and 2020. All studies included adult PLHIV in their samples. Twelve studies (eight quantitative and four quantitative parts of mixed methods) recruited the participants using a non-probability sampling technique. Half of the non-qualitative studies were interviewer-administered through paper or tablets. The majority of quantitative and (quantitative part of mixed methods) studies applied mixed logit analytic method whereas thematic analysis was applied in nearly half of qualitative and (qualitative part of mixed methods) studies (Table 1).

\section{Quantitative synthesis \\ Method of preference elicitation}

Patients' preferences were elicited with DCE/conjoint analysis method in 12 studies [23, 34, 36-38, 40, 43, 46, $48,50,52,54]$; rating exercise $[47,51]$, ranking exercise [49] and adaptive conjoint analysis [41, 55] in two studies each; and pair-wise comparison [45], and Best-Worst Scaling 1 [44] in one study each (Table 2).

\section{Attributes and dimensions}

The review showed that the number of attributes ranged from 3 to 26 per study. The median number of attributes used in all included quantitative studies was 6 (Inter Quartile Range 3). Regarding the attributes identified and selected in the included studies, they were clustered into the structure, process, and outcome dimensions of antiretroviral therapy service provision [22]. Overall, the studies used 11 different structure attributes, two process attributes, and ten outcome attributes (Table 3). When summed up, 149 attributes (95 outcome attributes, 47 structure attributes, and seven process attributes) were identified in the included studies (see Table 4). The attributes "Side effect" $(n=13)$ and "Efficacy" $(n=12)$ were the 


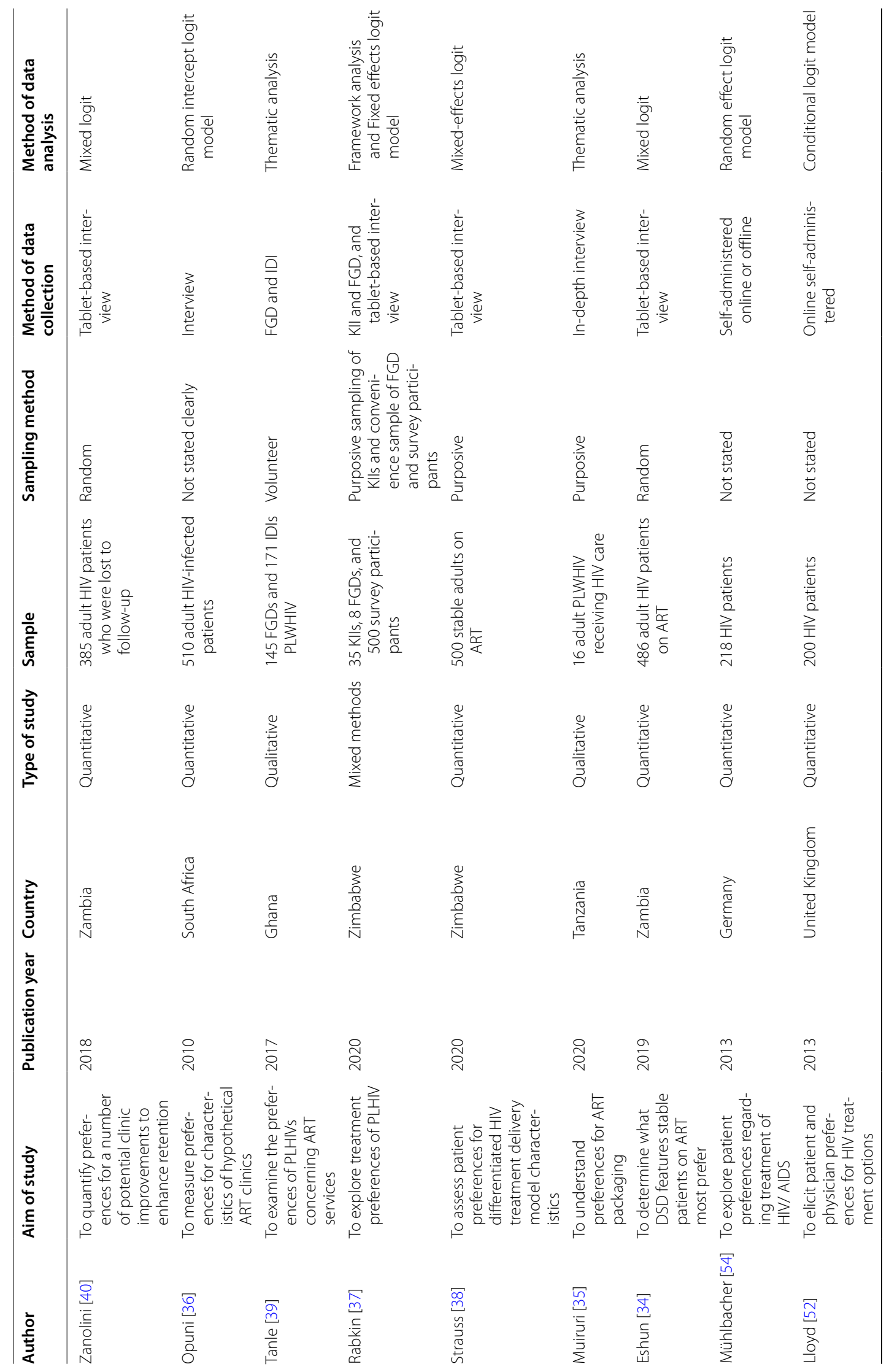




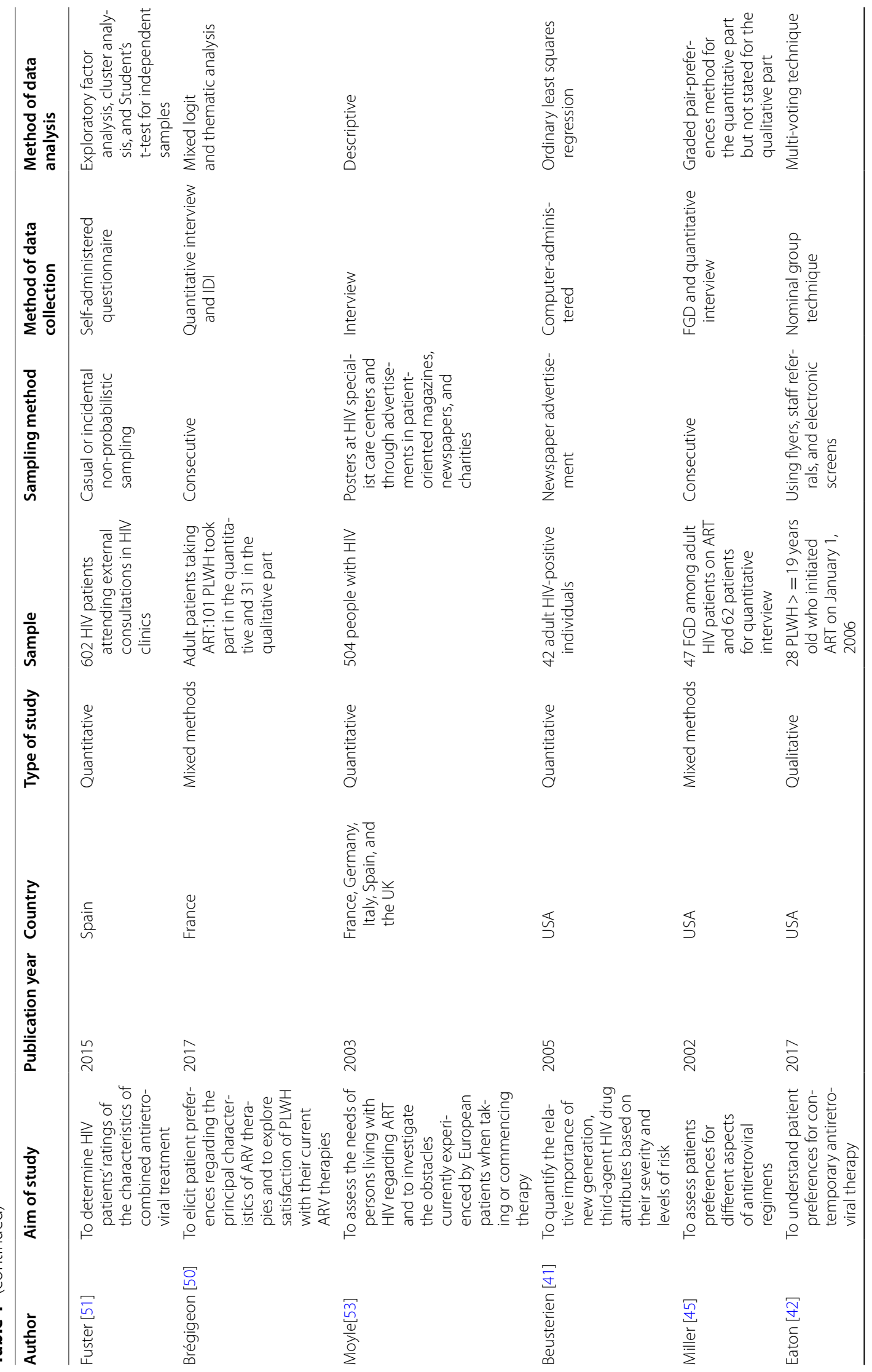


Belay et al. Cost Eff Resour Floc <wide> (2021) 19:56

Page 8 of 25

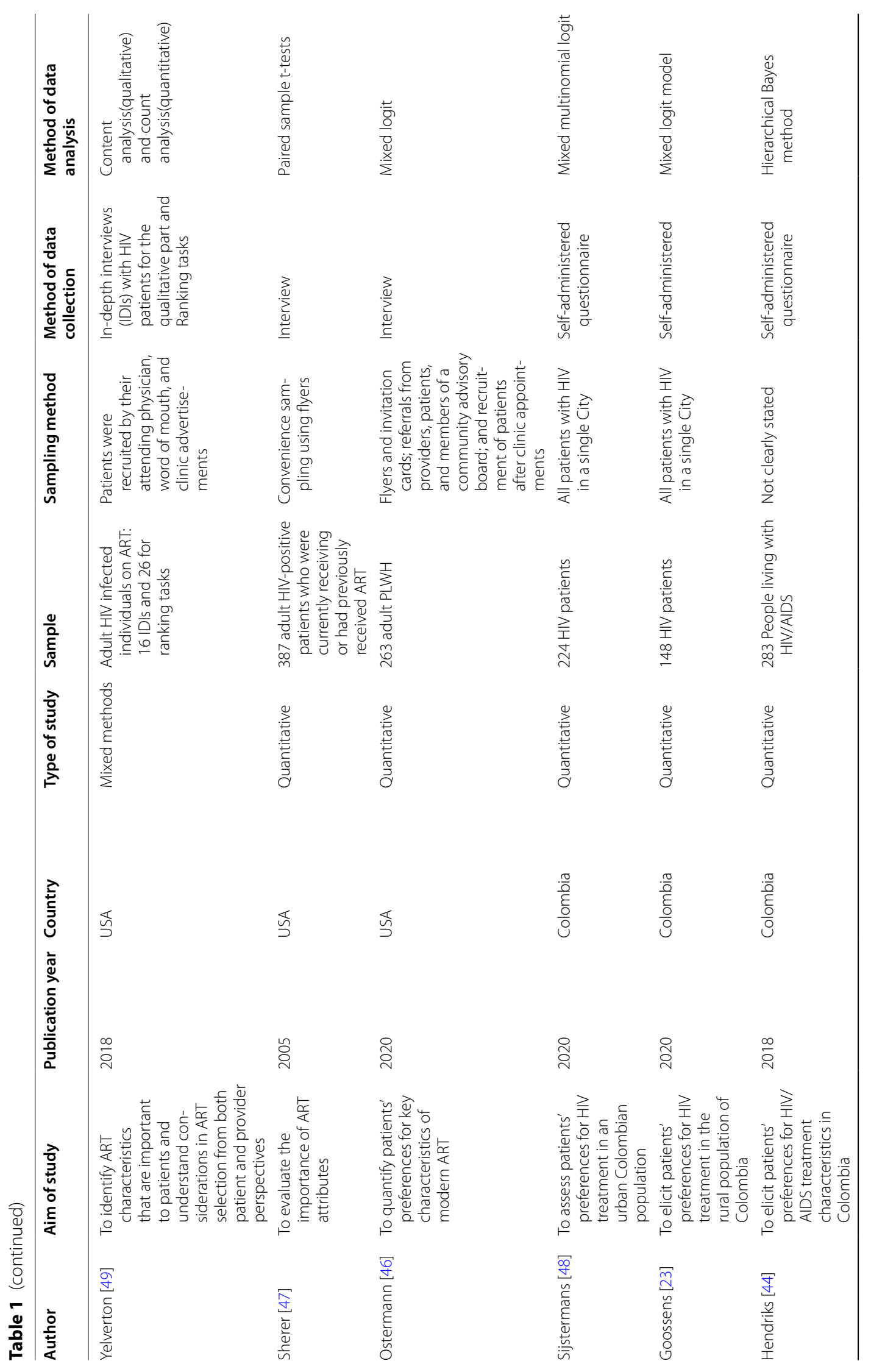




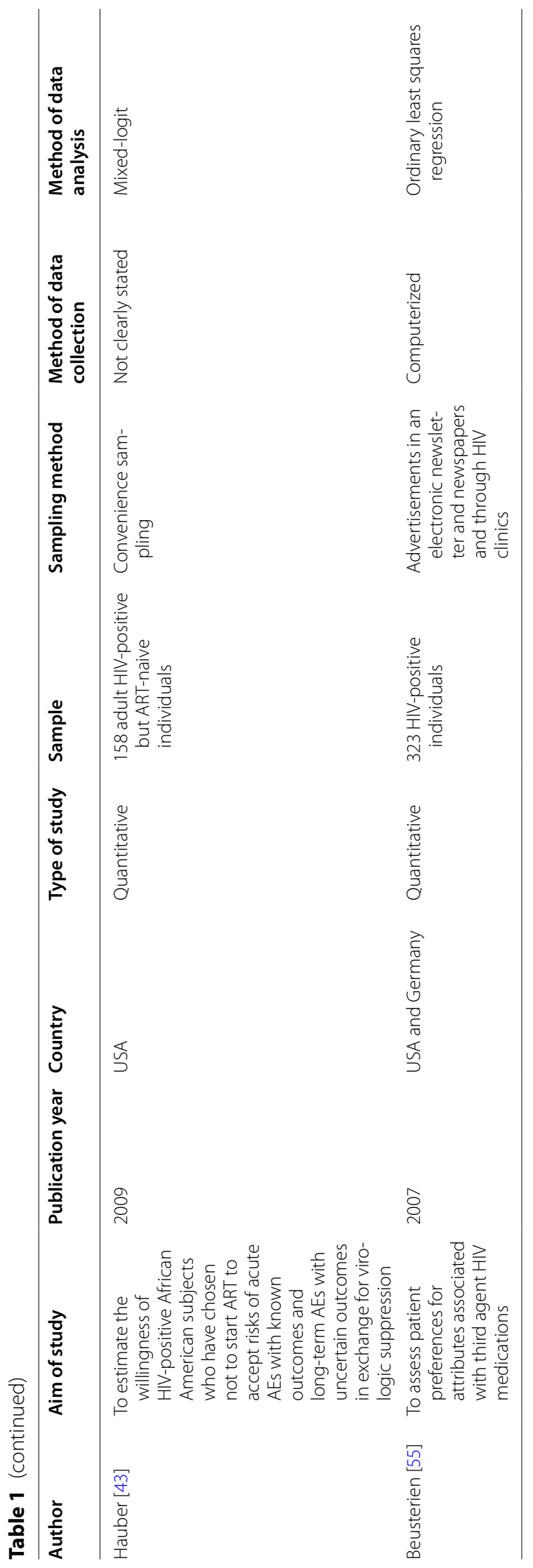

Table 2 Methods of preference elicitation

\begin{tabular}{ll}
\hline Method of preference elicitation & Number (\%) \\
\hline Discrete choice experiment/conjoint analysis & $12(60 \%)$ \\
Rating exercise & $2(10 \%)$ \\
Ranking exercise & $2(10 \%)$ \\
Adaptive conjoint analysis & $2(10 \%)$ \\
Pair-wise comparison & $1(5 \%)$ \\
Best Worst Scaling 1 & $1(5 \%)$ \\
\hline
\end{tabular}

two outcome attributes commonly used in the included studies. The most commonly used structure attribute was "Dosing and administration". Other attributes of this dimension that were frequently cited were "Waiting time at the clinic" ( $n=5)$, "Cost of visit" $(n=5)$, and "Frequency of visit" $(\mathrm{n}=4)$. "Staff attitude" was a commonly used process attribute $(n=4)$.

Table 3 Attributes and dimensions of antiretroviral therapy

\begin{tabular}{|c|c|}
\hline Attributes & $\begin{array}{l}\text { Number of } \\
\text { studies using } \\
\text { attribute }\end{array}$ \\
\hline \multicolumn{2}{|l|}{ Structure attributes $(n=11)$} \\
\hline Dosing and administration & 8 \\
\hline Waiting time at the clinic & 5 \\
\hline Cost of visit & 5 \\
\hline Frequency of visit & 4 \\
\hline Distance & 3 \\
\hline Operation time & 3 \\
\hline Location of service delivery & 3 \\
\hline Characteristics related to simplifications & 2 \\
\hline HIV clinic branding & 1 \\
\hline Buddy system & 1 \\
\hline Available clinical evidence or information & 1 \\
\hline \multicolumn{2}{|l|}{ Process attributes $(n=2)$} \\
\hline Staff attitude & 4 \\
\hline Participants/others seen at the same visit & 3 \\
\hline \multicolumn{2}{|l|}{ Outcome attributes $(n=10)$} \\
\hline Side effect & 13 \\
\hline Efficacy & 12 \\
\hline Long term health effect & 6 \\
\hline Regimen convenience & 5 \\
\hline Long duration of drug & 2 \\
\hline Interactions & 1 \\
\hline Therapy-free intervals possible & 1 \\
\hline The drug allows further therapy options & 1 \\
\hline It can also be used in case of comorbidities & 1 \\
\hline Pregnancy allowed & 1 \\
\hline
\end{tabular}




\section{Preferences for ART and relative attribute importance}

Four studies were excluded from attribute importance analysis due to a study reported mean preference rankings for regimen A and regimen B separately [45], there was a mean percent importance difference between Treatment-Naive and Treatment-Experienced participants [55], attributes were on different underlying scales [52], and the total number of ranks varied due to ties and exclusion of no important characteristics [49] (Table 4). The included 20 quantitative studies were based on a wide range of attributes related to ART service. There was heterogeneity in the results of preference estimates as the attributes were diverse across the included studies. Eight studies evaluated the dosing and administration of drugs. Overall, PLHIV needed a lower pill burden, smaller pill size, and lower frequency of drug-taking [44$47,49,53,54]$. The preference value ranking attached to the attribute "Clinic waiting time" varied, ranging from 1 to 6 among five studies [34, 36-38, 40]. In general, participants wanted a shorter duration of waiting time till the upcoming appointment. The participants choice rank for the attribute "Cost of visit" was heterogeneous across the five studies [23, 36-38, 48]. Participants did not want to pay for ART services. The evidence from 4 studies found that participants preferred less frequent clinic visits [34, 37, 38, 40]. Good provider attitude was highly valued by participants ranked either first in two studies $[37,38]$ and second in another two studies [36, 40]. The better efficacy of antiretrovirals (ARVs) was highly valued by participants, as shown by the 12 studies [23, 41, 43-45, 47, 48, 50-54]. Participants of the included studies also valued reduced or no side effects of ARVs as reported in the 13 included studies [23, 41, 43-49, 51-53, 55]. Similarly, participants had more value on low or no long-term health problems following taking medications as reported in the included six studies $[43,44,46,49,52$, 54] (Table 4).

\section{Qualitative synthesis}

Qualitative evidence about patient preferences for ART service provision was reported in seven studies [35, 37, $39,42,45,49,50]$. Data from qualitative studies were also organized into the structure, process, and outcome dimensions of the quality of care [22]. The thematic analysis produced ten themes under structure, three themes under process, and four themes under outcome dimension. However, the themes of inconvenience and novel ART delivery methods were categorized under both the structure and outcome dimensions. Table 5 summarizes initial concepts, emergent themes, final themes, supporting quotes, and dimensions of the final themes.

\section{Structure aspect of antiretroviral therapy}

Source of information on ART One study highlighted the source of information on ART could affect the preferences of PLHIV regarding the ART service provision [39].

Preferred place for ART service Two studies evaluated a preferred place for ART service. Participants preferred health facility-based service to home-based ART service since this model gives the patients the opportunities to have hospital education and preparation before initiating a drug, meet and interact with colleagues, discuss with providers, have access to psychosocial support, and avoid stigma and discrimination [37, 39].

Preferred person to deliver ART service One study asked participants whom they preferred to deliver ART service. Participants' choice of the service provider (health worker, trained PLHIV or foreigner) varied depending on the issues related to knowledge on ART, training, experience, encouraging patients to feel free to go to health facilities and avoiding a feeling of shyness, and maintaining confidentiality and interaction with patients [39].

Cost of ART medications Three studies evaluated the costs related to ART services [39, 42, 49]. Most patients preferred either a reduced or free drug cost. Some patients, however, were willing to pay whatever amount required as the drug is available.

Time spent at ART clinics and times (hours and days) of operation Two studies evaluated the waiting and clinic operation times at health facilities [37, 39]. Participants preferred shorter waiting times to obtain ART and flexible clinic hours.

Visit frequency One study asked participants about their preferred frequency of visits for ART pick-ups. Participants chose less frequent appointments (once or twice a year visit with larger supplies of ART dispensed at each visit) [37].

Pill burden and pill size One study evaluated the trade-off participants have on the pill size and pill burden. Some participants had a concern about swallowing big pills and most preferred single tablets. Some of them were willing to accept a higher pill burden in exchange for reduced side or long-term effects [49].

Drug administration Three studies examined the preference for drug administration [35, 42, 49]. Some participants preferred the drug in the form of a liquid, capsule, or injection to avoid swallowing of pills, lower the intake frequency and/or avoid a feeling of burden due to daily drug-taking and unpleasant drug taste.

ART packaging One study asked participants regarding their preference and recommendations for ART packaging [35, 37]. Participants identified three attributes of ART packaging that increased anticipated HIV stigma and prompted self-repackaging, including visual 
Table 4 Overview of attributes, levels, dimension of attributes, attribute importance, and most important attribute

\begin{tabular}{|c|c|c|c|c|}
\hline Authors & Attributes (levels) & $\begin{array}{l}\text { Dimension } \\
\text { of attribute }\end{array}$ & Attribute importance & Most important attribute \\
\hline \multirow[t]{5}{*}{ Zanolini } & Waiting time at the clinic $(1,3$, or $5 \mathrm{~h})$ & Structure & $4(5.20 \%)$ & ART supply is given at each refill \\
\hline & Distance from residence to the clinic $(5,10$, or $20 \mathrm{~km})$ & Structure & $3(6.20 \%)$ & \\
\hline & ART supply is given at each refill $(1,3$, or 5 months $)$ & Structure & $1(52.70 \%)$ & \\
\hline & $\begin{array}{l}\text { Hours of operation (morning only, morning and afternoon, or morning } \\
\text { and Saturday) }\end{array}$ & Structure & $5(3.10 \%)$ & \\
\hline & Staff attitude (rude or nice) & Process & $2(32.80)$ & \\
\hline \multirow[t]{12}{*}{ Beusterien $_{\mathrm{a}}$} & $\begin{array}{l}\text { Moderate to severe diarrhea (involving five or more loose stools per day } \\
(1 \%, 8 \% \text { or } 16 \% \text { chance) }\end{array}$ & Outcome & $5(7.10 \%)$ & Chance of developing resistance \\
\hline & Moderate to severe nausea $(5 \%, 10 \%$ or $14 \%$ chance) & Outcome & $6(6.90 \%)$ & \\
\hline & Moderate to severe vomiting $(2 \%, 5 \%$ or $7 \%$ chance) & Outcome & $10(4.70 \%)$ & \\
\hline & Moderate to severe rash $(1 \%, 5 \%$ or $10 \%$ chance) & Outcome & $9(5.00 \%)$ & \\
\hline & Moderate to severe jaundice( $<1 \%$ or $6 \%$ chance) & Outcome & $10(4.70 \%)$ & \\
\hline & Moderate to severe dizziness $(<1 \%, 3 \%$ or $6 \%$ chance) & Outcome & $7(5.80 \%)$ & \\
\hline & Moderate to severe depression( $<1 \%$ or $5 \%$ chance) & Outcome & $8(5.50 \%)$ & \\
\hline & Moderate to severe sleep problems ( $<1 \%, 10 \%$ or $25 \%$ chance) & Outcome & $3(8.60 \%)$ & \\
\hline & Virologic failure( $7 \%, 15 \%$ or $21 \%$ chance) & Outcome & $4(8.20 \%)$ & \\
\hline & Increasing cholesterol( very low, moderate, or high chance) & Outcome & $5(7.10 \%)$ & \\
\hline & $\begin{array}{l}\text { Chance of developing resistance(very low, low, moderate, high, or very } \\
\text { high chance) }\end{array}$ & Outcome & $1(10.30 \%)$ & \\
\hline & $\begin{array}{l}\text { Regimen convenience(Fosamprenavir,Fosamprenavir/ritonavir, Efavirenz, } \\
\text { Atazanavir, Nelfinavir,Lopinavir/ritonavir) }\end{array}$ & Outcome & $2(8.70 \%)$ & \\
\hline \multirow[t]{4}{*}{ Opuni } & Monthly ART price(12\$, 99\$, 149\$,199\$, or 298\$) & Structure & $3(23.50 \%)$ & Clinic waiting times \\
\hline & Clinic waiting times (30 min, 2 h, or 5 h) & Structure & $1(33.20 \%)$ & \\
\hline & $\begin{array}{l}\text { HIV clinic branding (not branded as HIV clinic in any way, discretely } \\
\text { branded as HIV clinic or clearly branded as HIV clinic) }\end{array}$ & Structure & $4(17.30 \%)$ & \\
\hline & $\begin{array}{l}\text { Clinic staff attitudes(kind, respectful, sympathetic, indifferent-neither } \\
\text { kind nor rude or rude, disrespectful, unsympathetic) }\end{array}$ & Process & $2(26.00 \%)$ & \\
\hline \multirow[t]{4}{*}{ Miller } & Adverse drug side effects & Outcome & N/A & N/A \\
\hline & Pill burden & Structure & & \\
\hline & Medication inconvenience & Outcome & & \\
\hline & Regimen potency & Outcome & & \\
\hline \multirow[t]{6}{*}{ Mühlbacher } & Life expectancy(maximal or moderate increase) & Outcome & $4(10.02 \%)$ & Emotional quality of life \\
\hline & $\begin{array}{l}\text { Long term side effects: improbable ( }<20 \% \text { of patients) or possible } \\
\text { ( } \geq 20 \% \text { of patients) }\end{array}$ & Outcome & $6(5.56 \%)$ & \\
\hline & Flexibility of dosing: max. 3 tablets/day or $\geq 4$ tablets/day & Structure & $5(6.19 \%)$ & \\
\hline & $\begin{array}{l}\text { Physical quality of life: diarrhea or nausea less frequent or diarrhea or } \\
\text { nausea more frequent }\end{array}$ & Outcome & $2(21.97 \%)$ & \\
\hline & $\begin{array}{l}\text { Emotional quality of life: disease not obvious for others or disease obvi- } \\
\text { ous for others }\end{array}$ & Outcome & $1(40.71 \%)$ & \\
\hline & $\begin{array}{l}\text { Social quality of life: participation in social life possible or participation in } \\
\text { social life restricted }\end{array}$ & Outcome & $3(15.55 \%)$ & \\
\hline \multirow[t]{13}{*}{ Beusterien $_{b}$} & Medication resistance & Outcome & N/A & N/A \\
\hline & Lipodystrophy & Outcome & & \\
\hline & Regimen convenience & Outcome & & \\
\hline & Moderate to severe rash & Outcome & & \\
\hline & Moderate to severe nausea & Outcome & & \\
\hline & Moderate to severe diarrhea & Outcome & & \\
\hline & Moderate to severe sleep disturbances & Outcome & & \\
\hline & Drug failure & Outcome & & \\
\hline & Moderate to severe vomiting & Outcome & & \\
\hline & Cholesterol elevation & Outcome & & \\
\hline & Moderate to severe jaundice & Outcome & & \\
\hline & Moderate to severe depression & Outcome & & \\
\hline & Moderate to severe dizziness & Outcome & & \\
\hline
\end{tabular}


Table 4 (continued)

\begin{tabular}{|c|c|c|c|c|}
\hline Authors & Attributes (levels) & $\begin{array}{l}\text { Dimension } \\
\text { of attribute }\end{array}$ & Attribute importance & Most important attribute \\
\hline \multirow[t]{8}{*}{ Lloyd } & $\begin{array}{l}\text { Treatment benefit: } 85 \%, 75 \% \text {, or } 65 \% \text { chance undetectable viral load at } \\
1 \text { year }\end{array}$ & Outcome & N/A & N/A \\
\hline & $\begin{array}{l}\text { Risk of rash: Treatment has a 1\%, 5\%, or 10\% risk of rash during the } \\
\text { first year }\end{array}$ & Outcome & & \\
\hline & $\begin{array}{l}\text { Risk of kidney stones: In the next five years 0, } 10 \text { per 1000, or } 37 \text { per } 1000 \\
\text { patients will develop kidney stones as a result of this treatment }\end{array}$ & Outcome & & \\
\hline & $\begin{array}{l}\text { Risk of jaundice: Treatment has a 1\%, 5\%, or 10\% risk of jaundice during } \\
\text { the first year }\end{array}$ & Outcome & & \\
\hline & $\begin{array}{l}\text { Risk of diarrhea: Treatment has a } 5 \%, 10 \% \text {, or } 17 \% \text { risk of diarrhea during } \\
\text { the first year }\end{array}$ & Outcome & & \\
\hline & $\begin{array}{l}\text { Risk of psychological effects: Treatment has a 10\%, 25\%, or 50\% risk } \\
\text { during the first year }\end{array}$ & Outcome & & \\
\hline & $\begin{array}{l}\text { Risk of heart attack: In the next ten years, } 0,6 \text { per 1000, or } 40 \text { per } 1000 \\
\text { patients will suffer a heart attack as a result of this treatment }\end{array}$ & Outcome & & \\
\hline & $\begin{array}{l}\text { Long term safety profile: Product safety has been established over 10, } \\
\text { 5, or } 3 \text { years }\end{array}$ & Outcome & & \\
\hline \multirow[t]{7}{*}{ Rabkin } & $\begin{array}{l}\text { Location of service delivery: Health facility/clinic close to home or } \\
\text { workplace ( } 10 \mathrm{~min} \text { travel), Health facility/clinic further from home or } \\
\text { workplace ( } 45 \mathrm{~min} \text { travel), Community-based DART services, or At } \\
\text { home }\end{array}$ & Structure & $3(\mathrm{OR}: 1.70)$ & Provider attitude \\
\hline & Participants/others seen at the same visit: Individual or Group & Process & 4 (OR:1.30) & \\
\hline & $\begin{array}{l}\text { Type of service provider: Professional health worker who is respectful } \\
\text { and understanding, Professional health worker who is not respectful } \\
\text { and understanding, Peer/layperson who is respectful and understand- } \\
\text { ing, or Peer/layperson who is not respectful and understanding }\end{array}$ & Process & $1(\mathrm{OR}: 2.40)$ & \\
\hline & $\begin{array}{l}\text { Times (days and hours) of operation: Workweek only (standard hours: } \\
8 \text { am-4 pm), Workweek with early morning hours (opens at } 5 \\
\text { am), Workweek with evening hours (open until } 8 \text { pm), or Work- } \\
\text { week + weekend hours ( } 7 \text { days a week, } 8 \text { am- } 4 \text { pm) }\end{array}$ & Structure & 7 (OR:1.00) & \\
\hline & $\begin{array}{l}\text { Frequency of routine visits for ART refill: Four times a year (every } \\
3 \text { months) or Two times a year (every } 6 \text { months) }\end{array}$ & Structure & 5 (OR:1.09) & \\
\hline & $\begin{array}{l}\text { Total time for a visit, including registration, wait times, and time with } \\
\text { providers. It does not include transportation time (30 min, } 1 \text { h, } 2 \text { h, } \\
\text { or } 4 \text { h) }\end{array}$ & Structure & 6 (OR:1.05) & \\
\hline & $\begin{array}{l}\text { The total cost of the visit including transportation, direct medical costs } \\
\text { (e.g., consultation or booking fee, lab costs if not available at a public } \\
\text { facility, non-ARV drug costs), costs of childcare: Free, } \$ 1, \$ 3 \text {, or } \$ 10\end{array}$ & Structure & $2(\mathrm{OR}: 2.36)$ & \\
\hline \multirow[t]{7}{*}{ Strauss } & $\begin{array}{l}\text { Location of service delivery: Health facility/clinic close to home or } \\
\text { workplace ( } 10 \text { min travel), Health facility/clinic further from home or } \\
\text { workplace ( } 45 \text { min travel), Community-based DART services, or At } \\
\text { home }\end{array}$ & Structure & 4 (OR:1.54) & Provider attitude \\
\hline & Participants/others seen at the same visit: Individual or Group & Process & 7 (OR: 0.60) & \\
\hline & $\begin{array}{l}\text { Type of service provider: Professional health worker who is respectful } \\
\text { and understanding, Professional health worker who is not respectful } \\
\text { and understanding, Peer/layperson who is respectful and understand- } \\
\text { ing, or Peer/layperson who is not respectful and understanding }\end{array}$ & Process & 1 (OR:4.68) & \\
\hline & $\begin{array}{l}\text { Times (days and hours) of operation: Workweek only (standard hours: } \\
8 \text { am-4 pm), Workweek with early morning hours (opens at } 5 \\
\text { am), Workweek with evening hours (open until } 8 \text { pm), or Work- } \\
\text { week + weekend hours ( } 7 \text { days a week, } 8 \text { am- } 4 \text { pm) }\end{array}$ & Structure & 6 (OR:1.10) & \\
\hline & $\begin{array}{l}\text { Frequency of routine visits for ART refill: Four times a year (every } \\
3 \text { months) or Two times a year (every } 6 \text { months) }\end{array}$ & Structure & 5 (OR: 1.207) & \\
\hline & $\begin{array}{l}\text { Total time for a visit, including registration, wait times, and time with } \\
\text { providers. It does not include transportation time(30 min, } 1 \text { h, } 2 \text { h, or } \\
4 \text { h) }\end{array}$ & Structure & $3(\mathrm{OR}: 1.70)$ & \\
\hline & $\begin{array}{l}\text { The total cost of the visit including transportation, direct medical costs } \\
\text { (e.g., consultation or booking fee, lab costs if not available at a public } \\
\text { facility, non-ARV drug costs), costs of childcare: Free, } \$ 1, \$ 3 \text {, or } \$ 10\end{array}$ & Structure & 2 (OR:1.77) & \\
\hline
\end{tabular}


Table 4 (continued)

\begin{tabular}{|c|c|c|c|c|}
\hline Authors & Attributes (levels) & $\begin{array}{l}\text { Dimension } \\
\text { of attribute }\end{array}$ & Attribute importance & Most important attribute \\
\hline \multirow[t]{3}{*}{ Yelverton } & ART administration characteristics & Structure & $\mathrm{N} / \mathrm{A}$ & \\
\hline & Side effects & Outcome & & \\
\hline & Long-term effects & Outcome & & \\
\hline \multirow[t]{9}{*}{ Sherer } & Lowering viral load & Outcome & $1(95 \%)$ & Lowering viral load \\
\hline & Raising CD4 & Outcome & $2(94 \%)$ & \\
\hline & Durability & Outcome & $2(94 \%)$ & \\
\hline & Pill burden & Structure & $7(70 \%)$ & \\
\hline & Dosing frequency & Structure & $6(74 \%)$ & \\
\hline & Resistance profile & Outcome & $3(89 \%)$ & \\
\hline & GISE & Outcome & $5(79 \%)$ & \\
\hline & Appearance SE & Outcome & $4(80 \%)$ & \\
\hline & Cholesterol SE & Outcome & $8(60 \%)$ & \\
\hline \multirow[t]{8}{*}{ Fuster } & Dosage & Structure & 4 (Mean: 8.41) & Efficacy \\
\hline & Characteristics related to simplifications & Structure & 8 (Mean: 6.40) & \\
\hline & Diet requirements & Structure & 7 (Mean: 7.16\%) & \\
\hline & Tolerance & Outcome & 5 (Mean: 8.18) & \\
\hline & Toxicity & Outcome & 2 (Mean:8.70) & \\
\hline & Interactions & Outcome & 6 (Mean:8.13) & \\
\hline & Efficacy & Outcome & 1 (Mean:9.55) & \\
\hline & Available clinical evidence or information & Structure & 3 (Mean:8.64) & \\
\hline \multirow[t]{4}{*}{ Ostermann } & $\begin{array}{l}\text { Dosing: Number of pills: one pill once daily, two pills once daily, three } \\
\text { pills once daily, one pill twice daily }\end{array}$ & Structure & $3(17.00 \%)$ & Side effect \\
\hline & $\begin{array}{l}\text { Administration: The pills are small, but you must take them with a meal } \\
\text { of at least } 400 \mathrm{kcal} \text {. The pills are large (about } 1 \text { inch), but you can take } \\
\text { them with or without a meal; or The pills are small, and you can take } \\
\text { them with or without a meal }\end{array}$ & Structure & $4(8.00 \%$ & \\
\hline & $\begin{array}{l}\text { Side effects: Moderate diarrhea, -Moderate sleeping problems,-Moder- } \\
\text { ate headaches, Moderate dizziness, Moderate depression or Jaundice }\end{array}$ & Outcome & $1(44.00 \%)$ & \\
\hline & $\begin{array}{l}\text { Long-term effect(over five years): Risk of heart attack, Risk of fracture } \\
\text { owing to weakened bones, Risk of new or worse kidney problems, } \\
\text { Risk of high cholesterol, or risk of high blood sugar }\end{array}$ & Outcome & $2(32.00 \%)$ & \\
\hline \multirow[t]{5}{*}{ Sijstermans } & $\begin{array}{l}\text { Effect on life expectancy: Large positive effects(Live many years more), } \\
\text { Moderate positive effects(Live a few more years), or Mild positive } \\
\text { effects: Live a short while more (a few months, less than two years) }\end{array}$ & Outcome & $2(23.00 \%)$ & Effect on physical activity \\
\hline & $\begin{array}{l}\text { Effect on physical activity: All physical activities without difficulty, Some } \\
\text { physical activities with difficulty, or All physical activities with difficulty }\end{array}$ & Outcome & $1(25.00 \%)$ & \\
\hline & $\begin{array}{l}\text { Risk of moderate side-effects: 1\%(Low risk of side-effects), } 2.5 \% \\
\text { (Medium risk of side-effects), or 5\% (Higher risk of side-effects) }\end{array}$ & Outcome & $4(17.30 \%)$ & \\
\hline & $\begin{array}{l}\text { Accessibility to the clinic: Less than } 2 \mathrm{~h} \text {, Between } 2 \text { and } 5 \mathrm{~h} \text {, or More } \\
\text { than } 5 \mathrm{~h}\end{array}$ & Structure & $3(20.50 \%)$ & \\
\hline & $\begin{array}{l}\text { Economic costs to access controls: Subsidized travel costs, Low travel } \\
\text { costs, paid by the patient or High travel costs, paid by the patient }\end{array}$ & Structure & $5(14.20 \%)$ & \\
\hline \multirow[t]{5}{*}{ Goossens } & $\begin{array}{l}\text { Effect on life expectancy: Large positive effects(Live many years more), } \\
\text { Moderate positive effects(Live a few more years), or Mild positive } \\
\text { effects: Live a short while more (a few months, less than two years) }\end{array}$ & Outcome & $2(26.00 \%)$ & Effect on physical activity \\
\hline & $\begin{array}{l}\text { Effect on physical activity: All physical activities without difficulty, Some } \\
\text { physical activities with difficulty, or All physical activities with difficulty }\end{array}$ & Outcome & $1(27.50 \%)$ & \\
\hline & $\begin{array}{l}\text { Risk of moderate side-effects: } 1 \% \text { (Low risk of side-effects), 2.5\%(Medium } \\
\text { risk of side-effects), or 5\%(Higher risk of side-effects) }\end{array}$ & Outcome & $4(16.70 \%)$ & \\
\hline & $\begin{array}{l}\text { Accessibility to the clinic: Less than } 2 \mathrm{~h} \text {, Between } 2 \text { and } 5 \mathrm{~h} \text {, or More } \\
\text { than } 5 \mathrm{~h}\end{array}$ & Structure & $3(22.10 \%)$ & \\
\hline & $\begin{array}{l}\text { Economic costs to access controls: Subsidized travel costs, Low travel } \\
\text { costs, paid by the patient or High travel costs, paid by the patient }\end{array}$ & Structure & $5(7.60 \%)$ & \\
\hline
\end{tabular}


Table 4 (continued)

\begin{tabular}{|c|c|c|c|c|}
\hline Authors & Attributes (levels) & $\begin{array}{l}\text { Dimension } \\
\text { of attribute }\end{array}$ & Attribute importance & Most important attribute \\
\hline \multirow[t]{6}{*}{ Eshun } & Location of ART pick-up: Clinic or Community & Structure & $4(7.70 \%)$ & Frequency of ART pick-up \\
\hline & Frequency of ART pick-up: Every month or Every 3 months & Structure & $1(62.14 \%)$ & \\
\hline & Time spent in picking up ART: $1 \mathrm{~h}$ total, $3 \mathrm{~h}$ total, or $6 \mathrm{~h}$ total & Structure & $3(10.30 \%)$ & \\
\hline & Time spent in seeing the doctor: $1 \mathrm{~h}$ total, $3 \mathrm{~h}$ total, or $5 \mathrm{~h}$ total & Structure & $5(1.10 \%$ & \\
\hline & $\begin{array}{l}\text { Adherence counseling: Individual counseling, Small group counseling } \\
\text { ( }<6 \text { people), or Large group counseling ( }>15 \text { people) }\end{array}$ & Process & $6(0.65 \%)$ & \\
\hline & Buddy system: Buddy system in place or No buddy system in place & Structure & $2(18.16 \%)$ & \\
\hline \multirow[t]{26}{*}{ Hendriks } & The drug has very high efficacy & Outcome & 1 (RIS:10.1) & The drug has very high efficacy \\
\hline & Maximum prolongation of life expectancy & Outcome & 2 (RIS: 9.7) & \\
\hline & Long duration of efficacy & Outcome & 3 (RIS: 7.4) & \\
\hline & The drug improves the physical state & Outcome & 4 (RIS: 6.0) & \\
\hline & The drug does not generate resistance & Outcome & 5(RIS: 5.4) & \\
\hline & Emotional and mental state improved & Outcome & 6 (RIS: 5.3) & \\
\hline & The dosing of the drug may vary & Structure & 7 (RIS: 4.9) & \\
\hline & Once-daily application & Structure & 8 (RIS: 4.5) & \\
\hline & The drug allows further therapy options & Outcome & 9 (RIS: 4.4) & \\
\hline & The drug can be taken along without problems & Outcome & 10 (RIS: 3.9) & \\
\hline & The drug does not affect the appearance & Outcome & 11 (RIS: 3.7) & \\
\hline & Long-term use of the drug is possible & Outcome & 12 (RIS: 3.5$)$ & \\
\hline & It can also be used in case of comorbidities & Outcome & 13 (RIS: 3.4) & \\
\hline & Pregnancy allowed & Outcome & 14 (RIS: 3.2) & \\
\hline & Simple application: only a few tablets & Structure & 15 (RIS: 3.1$)$ & \\
\hline & Long term (hidden) side effects are unlikely & Outcome & 16 (RIS: 2.9) & \\
\hline & The drug does not cause additional costs & Outcome & 17 (RIS: 2.6) & \\
\hline & The drug allows an improved mobility & Outcome & 17 (RIS: 2.6) & \\
\hline & Flexible application & Structure & 19 (RIS: 2.2) & \\
\hline & Social contact opportunities improved & Outcome & 20 (RIS: 2.0) & \\
\hline & Treatment does not require much time & Structure & 20 (RIS:2.0) & \\
\hline & Self-application of the drug is possible & Structure & 22 (RIS: 1.8) & \\
\hline & Therapy-free intervals possible & Outcome & 22 (RIS:1.8) & \\
\hline & Inconspicuous drug intake & Outcome & 24 (RIS: 1.7) & \\
\hline & Rarely occurring diarrhea & Outcome & 25 (RIS: 1.2) & \\
\hline & Rarely occurring nausea & Outcome & 26 (RIS:0.9) & \\
\hline \multirow[t]{5}{*}{ Hauber } & The chance that medicine does not work: $7 \%, 15 \%$ or $21 \%$ & Outcome & 5 & Chance of bone damage \\
\hline & Chance of having an allergic reaction: None, $1 \%, 8 \%$ or $12 \%$ & Outcome & 4 & \\
\hline & Chance of bone damage: None, $1 \%, 5 \%, 10 \%$ & Outcome & 1 & \\
\hline & Chance of kidney damage: None, $1 \%, 5 \%$ or $10 \%$ & Outcome & 2 & \\
\hline & $\begin{array}{l}\text { What happens if you have bone damage or kidney damage: You don't } \\
\text { know if the problem can be treated successfully, The problem can be } \\
\text { treated successfully, or The problem cannot be treated successfully }\end{array}$ & Outcome & 3 & \\
\hline \multirow[t]{5}{*}{ Moyle } & Side effects & Outcome & 1 (Rl:4.1) & Side effects \\
\hline & Potency & Outcome & $2(\mathrm{Rl}: 4.0)$ & \\
\hline & Dosing frequency & Structure & $3(\mathrm{Rl}: 2.6)$ & \\
\hline & Total daily pill load & Structure & $4(\mathrm{Rl}: 2.4)$ & \\
\hline & Number of pills per dose & Structure & 5 (RI:2.1) & \\
\hline
\end{tabular}

RIS: relative importance score; RI: relative importance; OR: odds ratio

identification, bulkiness, and the rattling noise produced by ART pill bottles.
Process aspect of antiretroviral therapy

Provider's attitude Two studies examined the providers' attitude towards PLHIV while delivering care. 
Participants needed a nice approach and respectful care and maintained confidentiality, and being requested to bring a family member of their own choice [37, 39].

Participants/others seen at the same visit One study evaluated the preference for individualized versus groupbased ART models. Participants preferred individualized ART models to group-based models due to privacy concerns [37].

Patient involvement, relationships with providers, and shared decision making One study examined the preference for patient involvement, relationships with their providers, and practice for shared decision making. Participants preferred good relationships and open communication with their providers [49].

\section{Outcome aspect of antiretroviral therapy}

Efficacy Three studies evaluated the efficacy of ARVs [42, $45,49]$. Participants needed their medication to control the HIV virus.

Side and or long-term effects One study examined both the side effects and long-term effects of taking the ART drugs [49]. Participants were concerned with the side effects of drugs. They preferred drugs with reduced or no side effects. They were willing to accept and or pay for reduced side effects [49]. Patients were also concerned with long-term effects and willing to accept and or pay for reduced long-term health effects [49].

Drug-drug interaction Two studies evaluated the participants' preference towards drug-drug interaction between ARVs or ARVs with other medications. Participants have a strong concern about drug-drug interactions $[42,49]$.

Besides, the attributes of inconvenience and novel ART delivery methods were clustered into structure and outcome dimensions of ART service delivery.

Inconvenience Two studies asked the participants' preference regarding convenience while taking medications. Participants mentioned their concern about inconvenience related to social life, food requirement, time in taking drugs, and child care activity $[45,49]$.

Novel ART delivery methods One study highlighted the importance of novel ART delivery approaches. Participants needed novel delivery of ART services, including coformulation of ART with chronic diseases drugs and injectable drug options [42].

\section{Integration of quantitative evidence and qualitative evidence}

The findings from individual quantitative and qualitative syntheses complement each other. Regarding the classification of attributes, the outcome aspect of ART took twothird of the share in the quantitative synthesis, whereas the structure aspect of ART took half of the share in the qualitative synthesis. The qualitative evidence explained well why the patients prefer or did not prefer a certain aspect of antiretroviral therapy service provision across the included quantitative studies. Attributes such as HIV clinic branding, accessibility to the clinic, time spent in seeing the doctor, and buddy system from the quantitative evidence were not explored in the qualitative studies and could therefore be investigated in future qualitative studies. On the other hand, the source of information on ART, packaging of ART and self-repackaging, and patient involvement, relationships with providers, and shared decision-making themes of the qualitative evidence were not tested in the quantitative studies. These factors would have implications for future discrete choice experiments. Figure 2 summarizes the attributes derived from both qualitative and quantitative evidence using a Donabedian framework.

\section{Discussion}

Overall, this systematic mixed studies review identified several attributes underlying antiretroviral therapy choice in PLHIV. The conceptual attributes used by previous studies were clustered into the structure, process, and outcome domains of ART service delivery. The type of attribute and its relative importance on patients' preferences varied across the included studies, which may have several reasons, such as the method of analysis, the selection procedure of the attributes and their levels, and/or the specific research question of the study.

\section{Structure attributes}

In this review, health facility-based models of ART were highly valued than community-based models. It is consistent with previous evidence $[16,56]$. This type of valuation could continue overstretching the existing health system and might create a barrier in scaling up ART to where PLHIV live and work hence deter achievement of 95-95-95 targets by 2030. Respondents' choice of service provider type was influenced by the providers' characteristics which are in line with previous evidence [57]. Healthcare workers were more preferred for their knowledge of drugs and disease, whereas trained PLHIV and foreigners (outside of their community) were preferred for their breaking down barriers and maintaining confidentiality. This highlights a difference in patient priority and has implications for patient-centered care. Regarding the source of information for ART, the majority of the participants in this review received information from health care providers, whereas some of them got information from TV and Radio. This finding is in line with a previous nationwide study where the majority of the 
participants ranked doctors in their top three information sources, HIV positive counselors and magazines next, and brochures and newsletters as last [58].

An increased total cost of visits (transportation, direct medical costs, and costs of childcare) was negatively associated with respondents' choice of ART service, which is comparable with the previous systematic review [59]. This has implications for access to service and insurance coverage and further progress towards universal health coverage. Furthermore, less frequent clinic visit was highly preferred by respondents and is comparable with earlier reviews $[16,60]$. The WHO's differentiated service delivery initiative has also recognized the positive impacts of appointment spacing ART delivery models on patient and health system efficiencies [10]. Similarly, shorter travel distance was found to be preferred by participants, which is comparable with the previous review [16]. This has implications for access to service and demand for increased investment in community-based ART distribution models.

Regarding the waiting time to access antiretroviral drugs and clinical consultations, participants had more value on reduced waiting time, as similarly reported in previous reviews $[14,16]$. This has implications for patient satisfaction. Similarly, respondents chose flexible or convenient clinic hours, including extra hours and weekends, which is consistent with an earlier systematic review [14]. This has policy implications on the health workforce and other resource allocation to increase service availability beyond the standard routine practice hours and days. Furthermore, participants preferred the availability of a buddy system (others take the drug in case of severe illness). From a policy perspective, this suggests that involving family members in care to maintain continuity of care as needed might improve patient drug adherence hence good treatment outcomes. HIV clinic branding was negatively associated with patient preference for ART service provision. This has implications for stigma reduction and care optimization since clinic branding might be a barrier to ART service utilization and adherence.

Reduction in pill burden was valued highly by patients. However, this would not continue as a concern since the current medication is based on fixed-dose single-tablet combinations. Besides, a smaller pill size was preferred by respondents. This implies for future patient-centered pharmaceutical drug formulation to ease medication swallowing. Patients also preferred injectable or liquid forms of drugs to reduce pill burden, avoid swallowing pills and unpleasant taste or reduce intake frequency. This has implications for drug innovators to bring new ARV options. In this review, patients had less preference on current ART packaging due to privacy issues and prioritized practicing self-repackaging. However, this could have a negative effect on the patient outcomes as a previous study reported an association of patient-initiated repackaging of ART with virological failure and ART drug resistance [61]. A patient-friendly pharmaceutical pack design is needed in future drug development investments, as inferred from this review.

\section{Process attributes}

Good providers' attitude was found positively associated with patients' choice for ART service. This is consistent with the previous reviews $[14,16]$. This has important implications for bringing interventions to continue enhancing providers' empathy and positivity. Similarly, patients valued more their involvement and making a shared decision in HIV treatment and having good relationships with their providers, which is in line with the WHO's people-centered health care policy framework [62] and a previous review [14]. This inferred that the shared decision model is appropriate in complex ART decisions. In this review, PLHIV were willing to accept individualized models than group-based models to reduce HIV stigma and discrimination even though group-based models were initially designed for reducing patients' waiting time while receiving care. It is in line with a systematic review undertaken in sub-Saharan Africa [59]. This highlights much effort is needed to scale up group-based ART initiatives to enhance better patient outcomes.

\section{Outcome attributes}

In this systematic review, patients highly valued effective ARV drugs, which is in line with a previous systematic review [63]. Also, the long duration of the drugs was highly valued. Likewise, increased quality and quantity of life were valued more considered as the important attributes underlying HIV drugs. Beyond the potency, increased life expectancy, and quality of life benefits of ARVs, patients also preferred the drugs to be with no or reduced side effects, long-term health problems, and drug-drug interactions. This is in agreement with the previous systematic review [63]. The WHO's consolidated guidelines on the use of antiretroviral drugs for treating and preventing HIV infection [5] also acknowledged the above-mentioned attributes of HIV medications. This has implications for accommodating patient preferences in future drug discovery and development efforts by balancing the benefits and harms of treatment options.

Besides, this review found that novel ART delivery methods and inconvenience while taking medications as the relevant attributes affecting the preference of PLHIV on ART service delivery. A study conducted in the United 


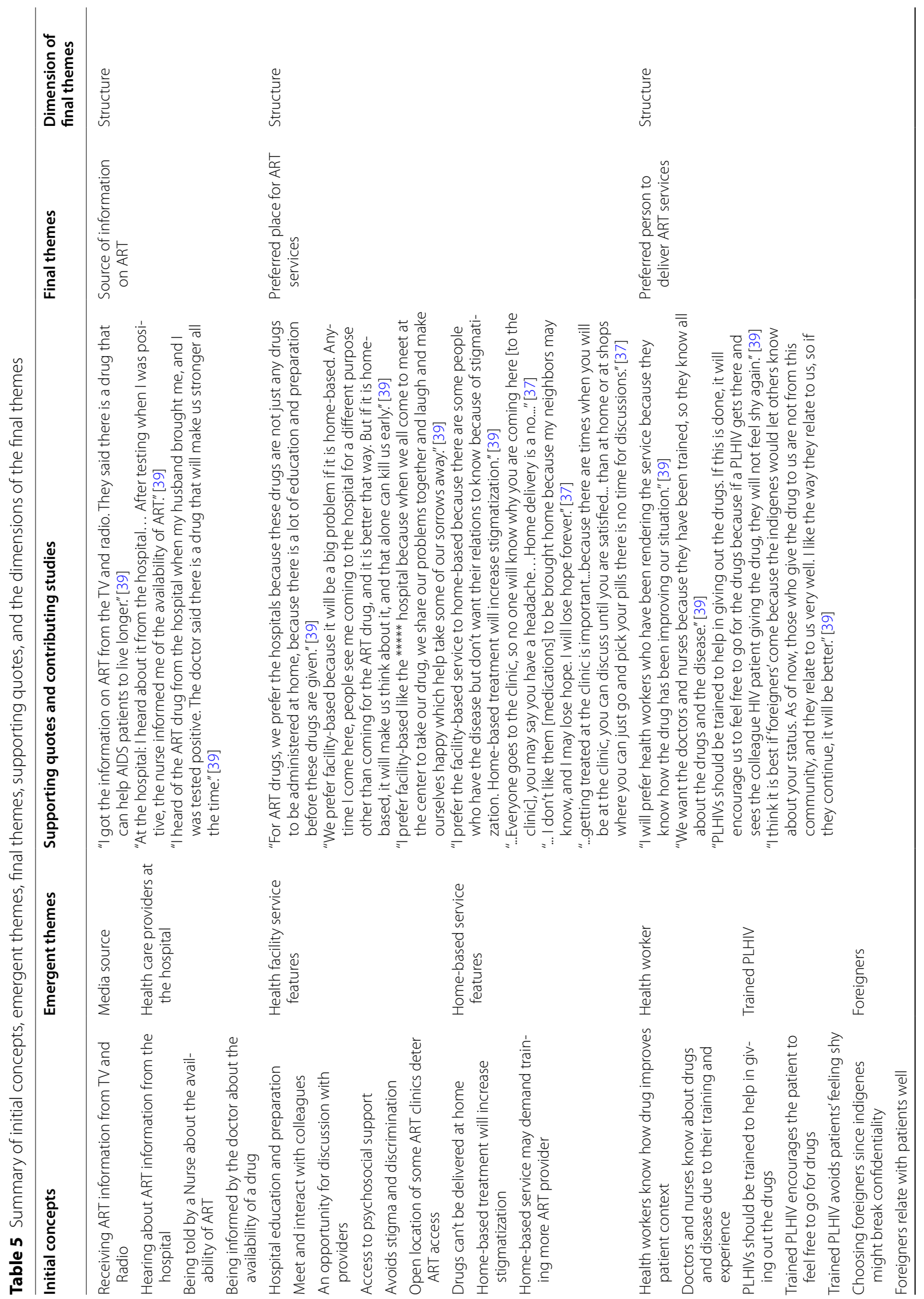




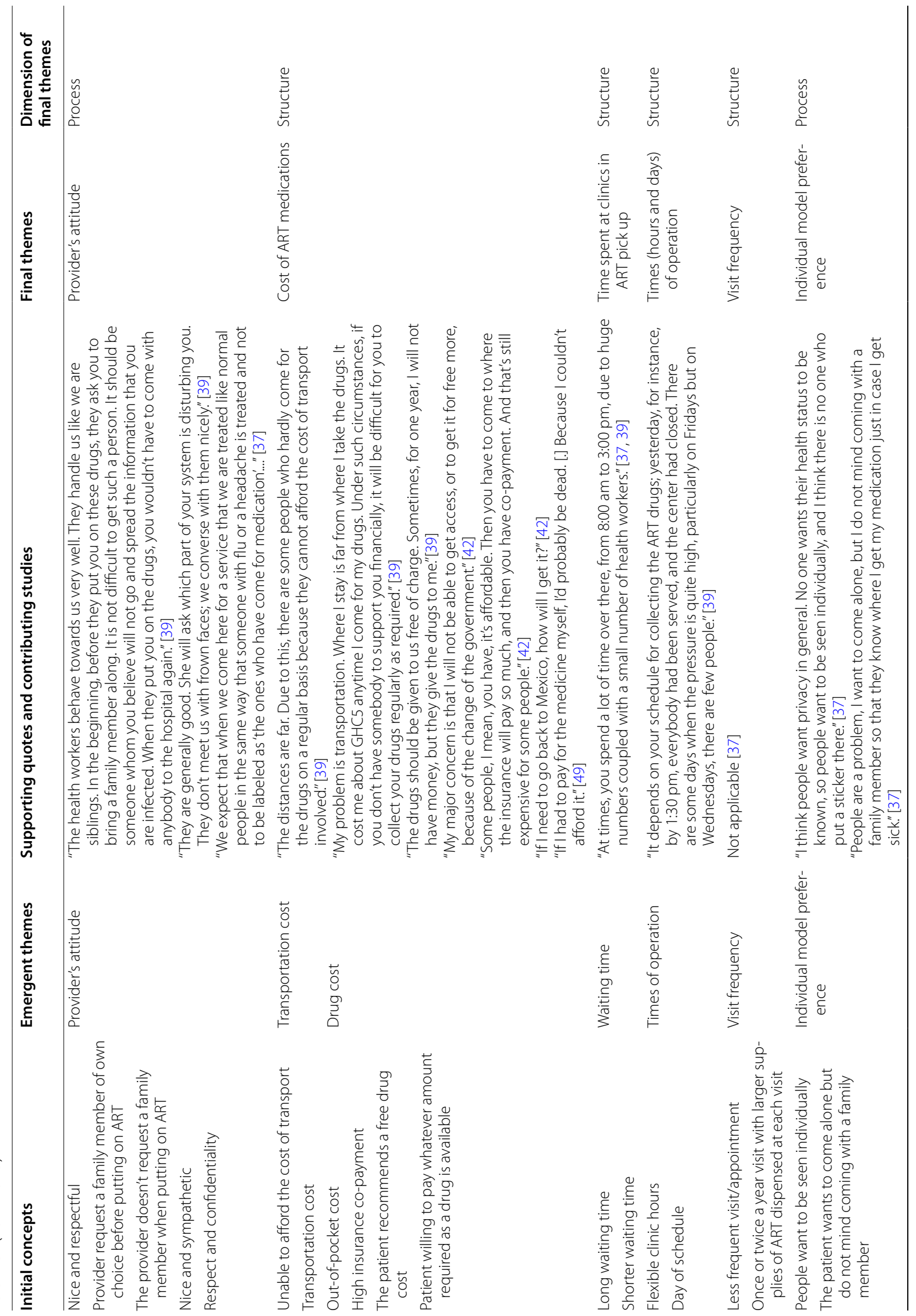




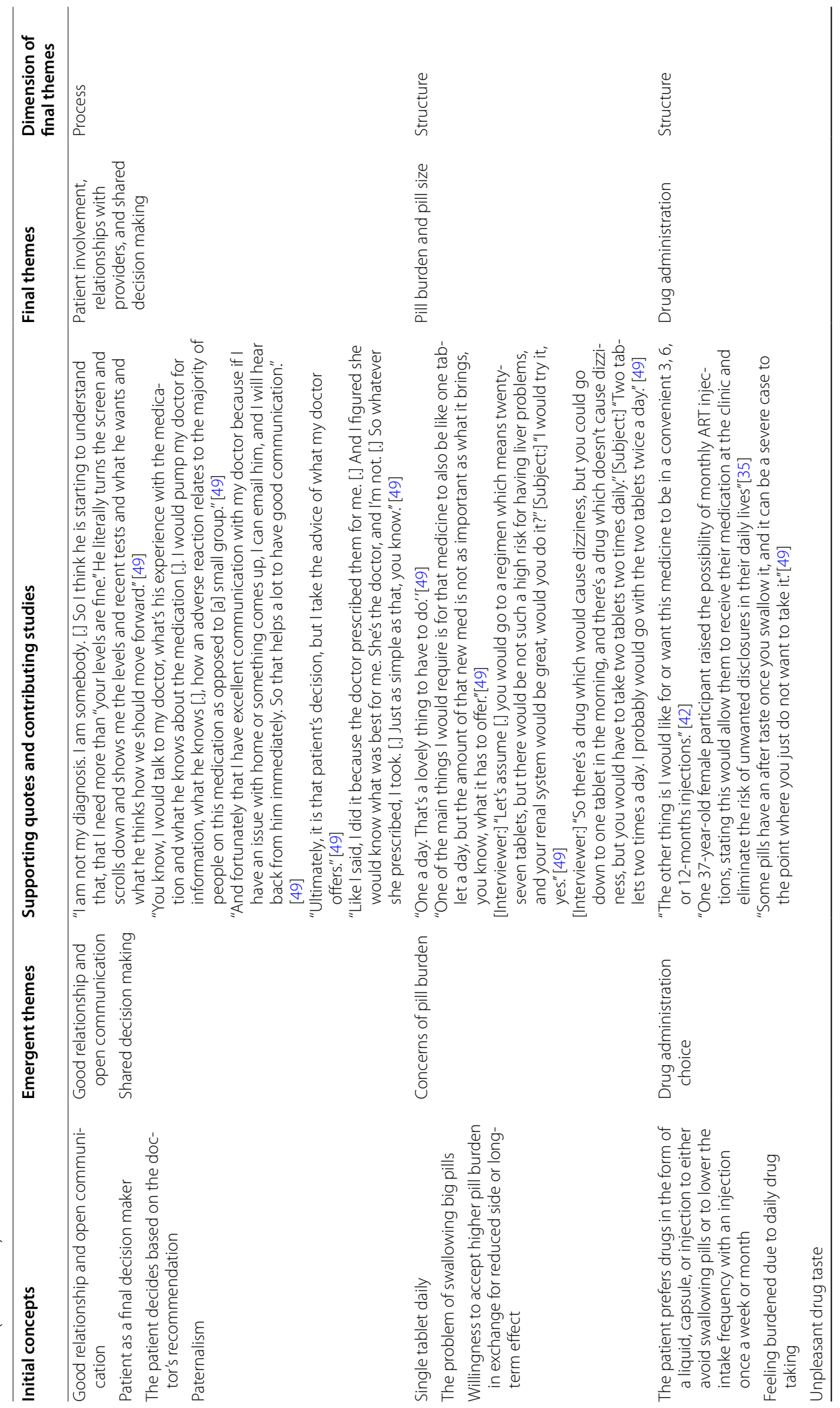




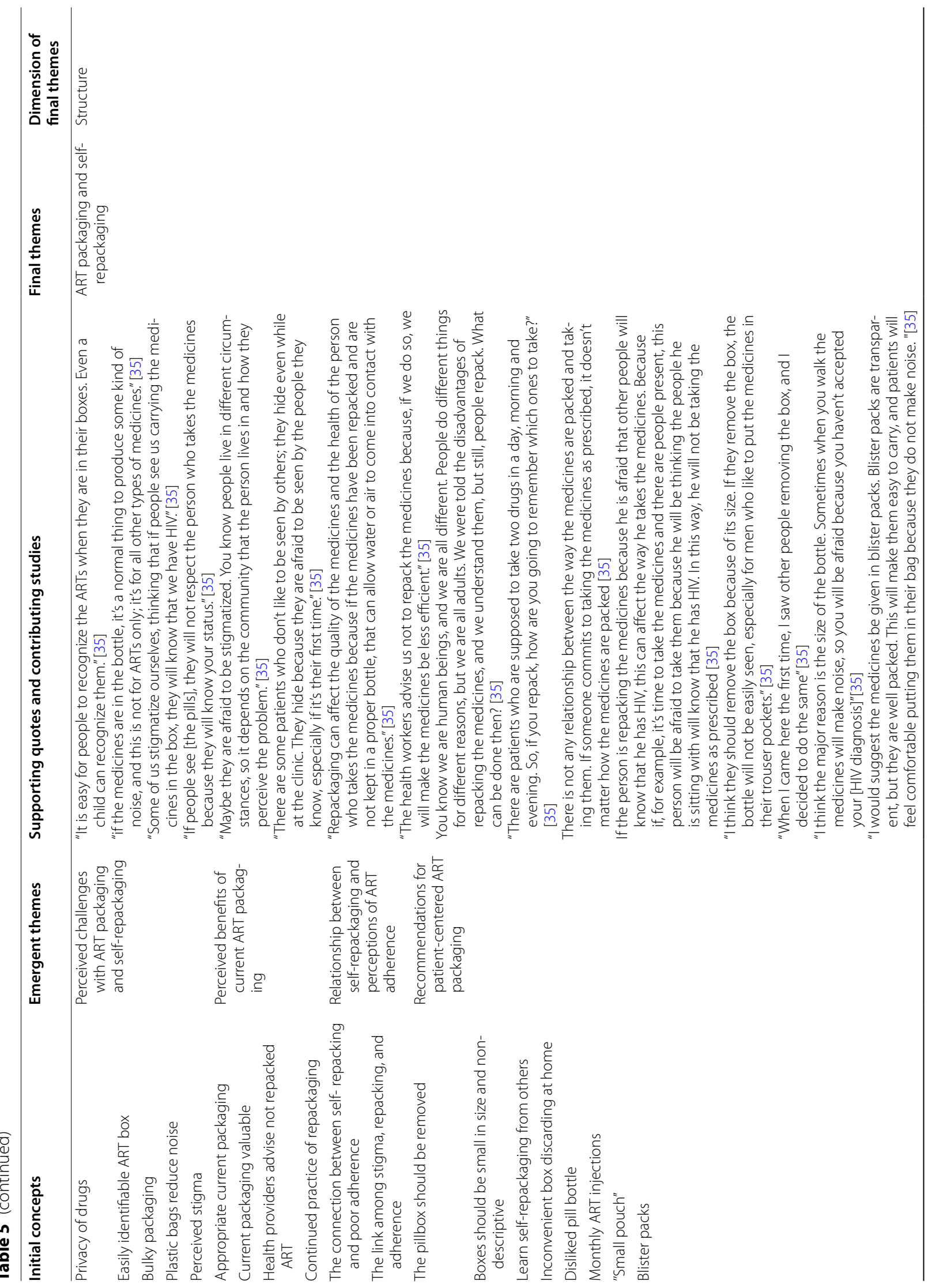




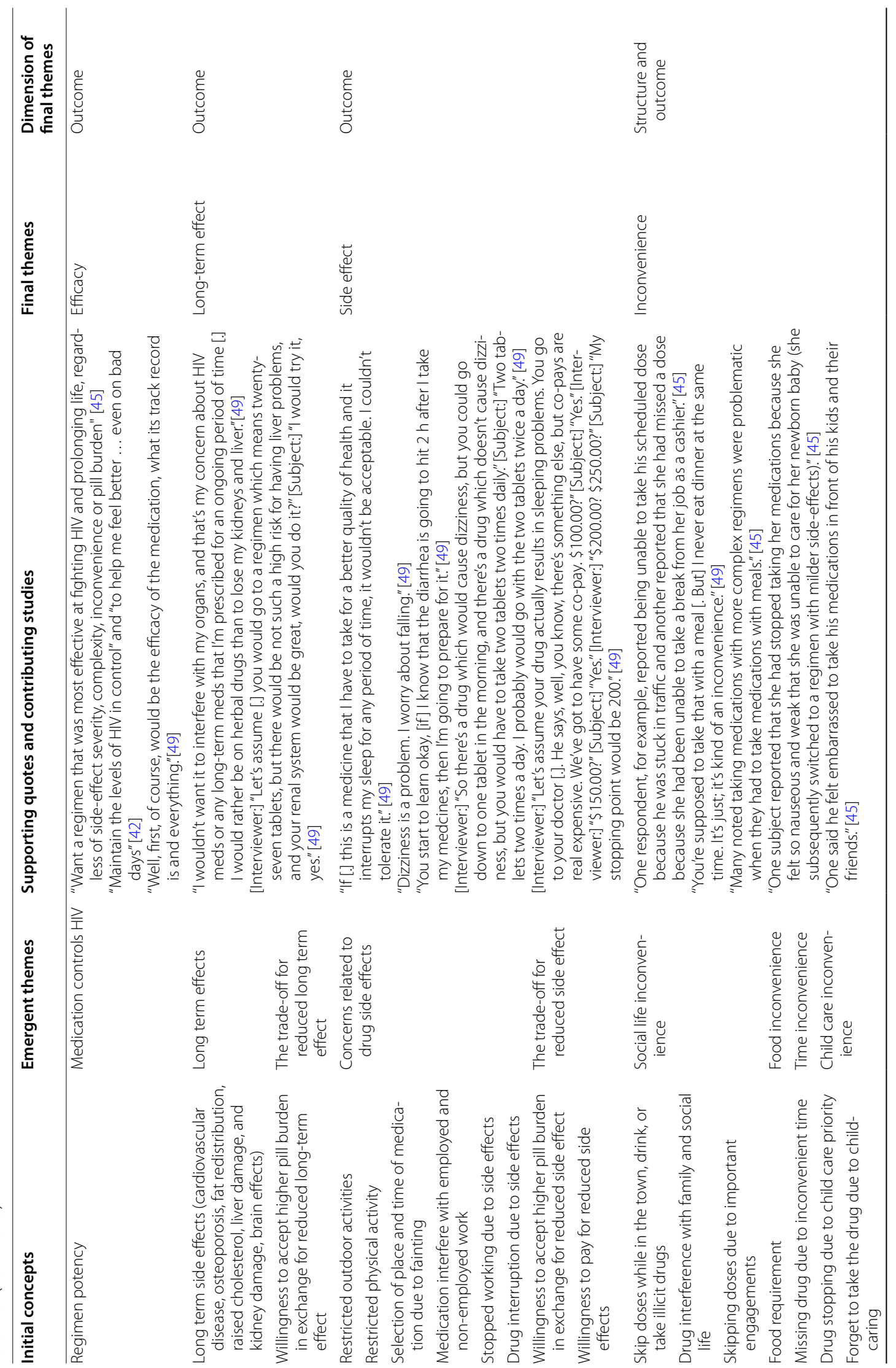




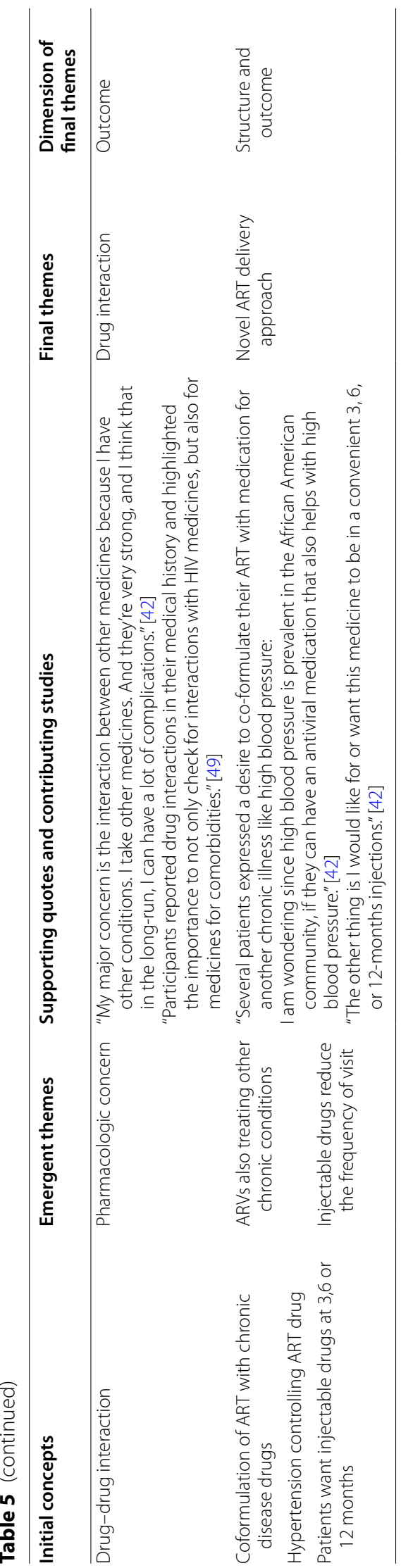




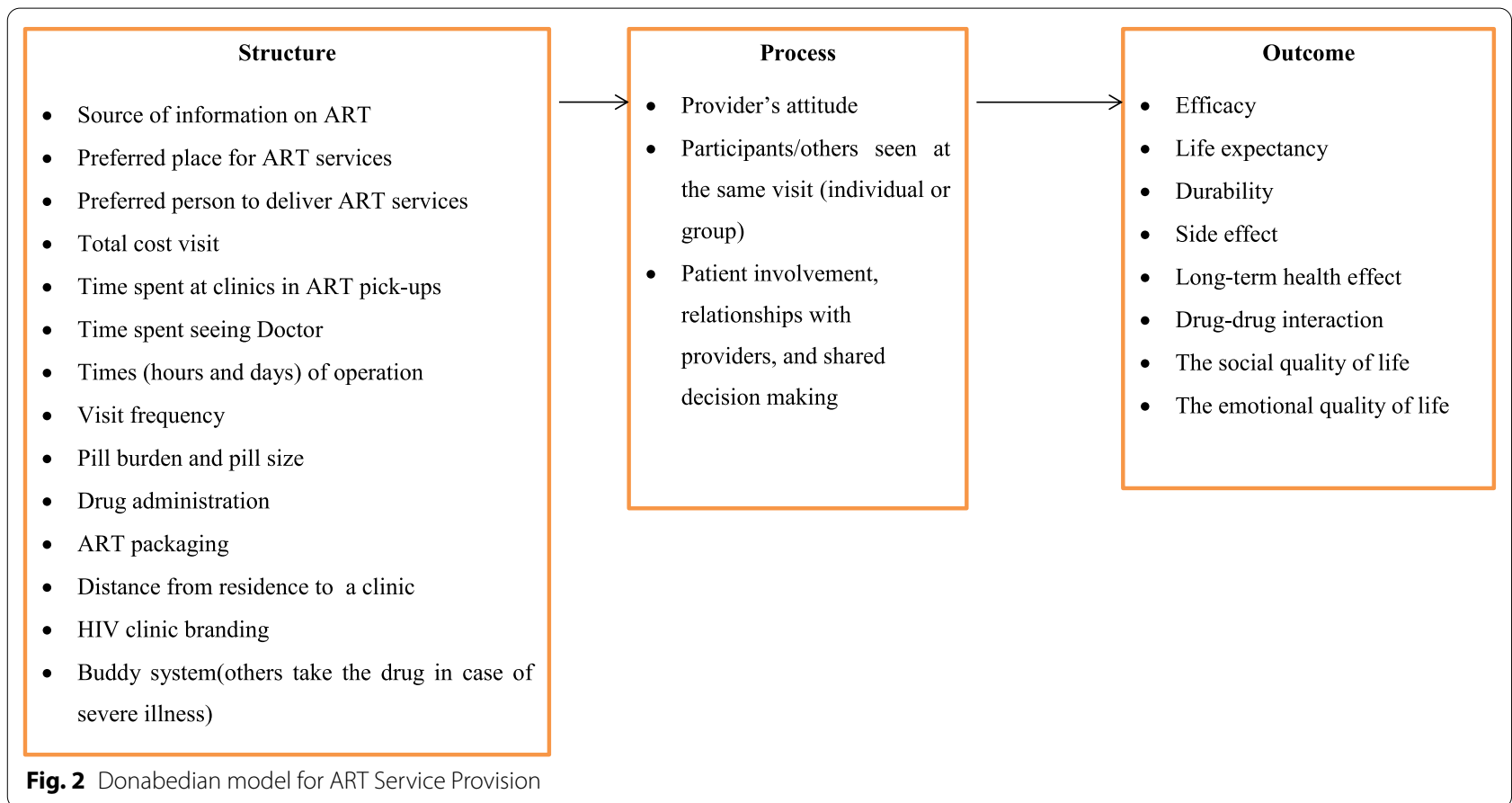

States and Canada supports our review that patients preferred the long-acting injectable treatment regimen to avoid daily taking of drugs or reminders of having HIV [64]. Similarly, a systematic review found that HIV treatment fatigue occurred due to inconvenient scheduling, adverse side effects, and lifestyle changes which might affect patients' choice of ART service delivery [65].

\section{Strengths and limitations of the review}

This mixed-methods systematic review incorporated studies using both qualitative and quantitative methodologies to get a comprehensive understanding of the aspects of ART service delivery considered important by PLHIV in previous studies. This has the advantage of generating more robust implications for practice, research, and policymaking. This review has two noticeable limitations. First, as with the limitations of any systematic review, there is the possibility of incomplete retrieval of identified research due to the scope of the search terms and the databases searched. Second, there might be a probability of selection bias as only published studies in the English language were included.

\section{Conclusions}

This review gives an overview of patients' preferences for ART service provision features. Patients on ART had different values on the structure, process, and outcome components of antiretroviral therapy. The relative importance of each attribute used in the previous studies, as well as the patients' preferences for ART service delivery characteristics, varied across the included studies. Thus, policymakers and practitioners should be aware of the aspects of ART that are considered as particularly important by the patients and the trade-offs, they are willing to make between various aspects of ART. Moreover, this review can be helpful for researchers planning to undertake a DCE in ART service since it gives a comprehensive picture of ART service delivery attributes and levels.

\section{Abbreviations}

AIDS: Acquired Immunodeficiency Syndrome; ART: Antiretroviral therapy; ARV: Antiretroviral; DCE: Discrete choice experiment; HIV: Human Immunodeficiency Virus; PLHIV: People living with HIV; WHO: World Health Organization.

\section{Supplementary Information}

The online version contains supplementary material available at https://doi. org/10.1186/s12962-021-00310-7.

Additional file 1. Search strategy for PubMed, Embase, Web of Science, and CINAHL databases.

Additional file 2. Data extraction tool.

Additional file 3. Mixed Methods Appraisal Tool (MMAT) checklist.

Acknowledgements

We acknowledge the authors of the articles included in this review.

\section{Authors' contributions}

All authors developed the literature search strategy. YAB and FAT conducted the literature search. YAB and MY assessed the quality of the studies. YAB 
and AA extracted the data. The manuscript was drafted by YAB and FAT. All authors read and approved the final manuscript.

\section{Funding}

No funding was received for this study.

\section{Availability of data and materials}

All data generated or analyzed during this study are included in this published article and its additional files.

\section{Declarations}

\section{Ethics approval and consent to participate}

Not applicable.

\section{Consent for publication}

Not applicable.

\section{Competing interests}

The authors declare that they have no competing interests.

\section{Author details}

${ }^{1}$ Department of Public Health, College of Health Sciences, Debre Markos University, Debre Markos, Ethiopia. ${ }^{2}$ Department of Health Systems and Policy, Institute of Public Health, College of Medicine and Health Sciences, University of Gondar, Gondar, Ethiopia. ${ }^{3}$ Department of Accounting, Finance, and Economics, Griffith University, Brisbane, Australia.

Received: 19 April 2021 Accepted: 16 August 2021

Published online: 30 August 2021

\section{References}

1. Joint United Nations Programme on HIV/AIDS. Global HIV \& AIDS statistics — Fact sheet 2021 https://www.unaids.org/en/resources/fact-sheet. Accessed 13 Mar 2021.

2. World Health Organization. HIV/AIDS_Fact sheet 2020 https://www.who. $\mathrm{int} /$ news-room/fact-sheets/detail/hiv-aids. Accessed 31 July 2020.

3. Joint United Nations Programme on HIV/AIDS. AIDS and the sustainable development goals 2020 https://www.unaids.org/en/AIDS_SDGs. Accessed 15 June 2020.

4. Joint United Nations Programme on HIV/AIDS. 90-90-90: an ambitious treatment target to help end the AIDS epidemic. Geneva: Unaids; 2014.

5. World Health Organization. Consolidated guidelines on the use of antiretroviral drugs for treating and preventing HIV infection: recommendations for a public health approach. 2nd ed. Geneva: World Health Organization; 2016.

6. El-Sadr WM, Rabkin M, DeCock KM. Population health or individualized care in the global AIDS response: synergy or conflict? AIDS 2016;30(14):2145.

7. The International AIDS Society (IAS). What is differentiated ART delivery? 2021 https://differentiatedservicedelivery.org/. Accessed 29 Jan 2021

8. Duncombe C, Rosenblum S, Hellmann N, Holmes C, Wilkinson L, Biot M, et al. Reframing HIV care: putting people at the centre of antiretroviral delivery. Trop Med Int Health. 2015;20(4):430-47.

9. Grimsrud A, Bygrave H, Doherty M, Ehrenkranz P, Ellman T, Ferris R, et al. Reimagining HIV service delivery: the role of differentiated care from prevention to suppression. J Int AIDS Soc. 2016;19(1):21484.

10. International AIDS Society. Differentiated care for HIV: a decision framework for antiretroviral therapy delivery. Durban: International AIDS Society Durban; 2016

11. World Health Organization. Key considerations for differentiated antiretroviral therapy delivery for specific populations: children, adolescents, pregnant and breastfeeding women and key populations. Geneva: World Health Organization; 2017 2017. Contract No.: WHO/HIV/2017.34.

12. Zanolini A, Sikombe K, Sikazwe I, Eshun-Wilson I, Somwe P, Moore CB, et al. Understanding preferences for HIV care and treatment in Zambia: evidence from a discrete choice experiment among patients who have been lost to follow-up. PLoS Med. 2018;15(8):e1002636.
13. Lancsar E. Deriving welfare measures from stated preference discrete choice modelling experiments, CHERE Discussion Paper No 48. 2002.

14. Cooper V, Clatworthy J, Youssef E, Llewellyn C, Miners A, Lagarde M, et al. Which aspects of health care are most valued by people living with HIV in high-income countries? A systematic review. BMC Health Serv Res. 2016;16(1):1-15.

15. Humphrey JM, Naanyu V, MacDonald KR, Wools-Kaloustian K, Zimet GD. Stated-preference research in HIV: a scoping review. PLoS ONE. 2019;14(10):e0224566.

16. Eshun-Wilson I, Kim H, Schwartz S, Conte M, Glidden D, Geng EH. Exploring relative preferences for HIV service features using discrete choice experiments: a synthetic review. Curr HIV/AIDS Rep. 2020;17:1-11.

17. Liberati A, Altman DG, Tetzlaff J, Mulrow C, Gøtzsche PC, loannidis JP, et al The PRISMA statement for reporting systematic reviews and meta-analyses of studies that evaluate health care interventions: explanation and elaboration. J Clin Epidemiol. 2009;62(10):e1-34.

18. Hong QN, Pluye P, Fàbregues S, Bartlett G, Boardman F, Cargo M, et al. Mixed methods appraisal tool (MMAT), version 2018. Educ Inf. 2018;1148552:10

19. Stern C, Lizarondo L, Carrier J, Godfrey C, Rieger K, Salmond S, et al. Methodological guidance for the conduct of mixed methods systematic reviews. JBI Evid Synth. 2020;18(10):2108-18.

20. Lizarondo L SC, Carrier J, Godfrey C, Rieger K, Salmond S, et al,. Chapter 8: Mixed methods systematic reviews. In: Aromataris E, Munn Z (Editors). JBI Manual for Evidence Synthesis JBI; 2020.

21. Thomas J, Harden A. Methods for the thematic synthesis of qualitative research in systematic reviews. BMC Med Res Methodol. 2008;8(1):1-10.

22. Donabedian AJJ. The quality of care: how can it be assessed? JAMA. 1988:260(12):1743-8

23. Goossens AJ, Cheung KL, Sijstermans E, Conde R, Gonzalez JG, Hiligsmann MJ. A discrete choice experiment to assess patients' preferences for HIV treatment in the rural population in Colombia. J Med Econ. 2020;23(8):803-11.

24. Hauber AB, González JM, Groothuis-Oudshoorn CG, Prior T, Marshall DA, Cunningham C, et al. Statistical methods for the analysis of discrete choice experiments: a report of the ISPOR conjoint analysis good research practices task force. Value in Health. 2016;19(4):300-15.

25. Lancsar E, Louviere J, Flynn T. Several methods to investigate relative attribute impact in stated preference experiments. Soc Sci Med. 2007;64(8):1738-53

26. Gazzard B, Ali S, Muhlbacher A, Ghafouri N, Maggiolo F, Golics C, et al. Patient preferences for characteristics of antiretroviral therapies: results from five European countries. J Int AIDS Soc. 2014;17(4 Suppl 3):19540.

27. Tsutomu K, Yasuki K. Patients' preference toward receiving antiretroviral therapy in Thailand. Kyorin University; 2015. https://kaken.nii.ac.jp/en/ report/KAKENHI-PROJECT-25460813/25460813seika/. Accessed 29 Jan 2021.

28. Yelverton V, Ostermann J, Hobbie A, Madut D, Mühlbacher A, Thielman N. prioritizing patient-relevant attributes of HIV medications: a mixed methods approach. Value Health. 2017;20(9):A793.

29. Kruk ME, Riley PL, Palma AM, Adhikari S, Ahoua L, Arnaldo C, et al. How can the health system retain women in HIV treatment for a lifetime? A discrete choice experiment in Ethiopia and Mozambique. PLoS ONE. 2016;11(8):e0160764.

30. Hiligsmann M, Cheung KL. Understanding patients' preferences for HIV treatment among rural and urban Colombian patients. Milton Park: Taylor \& Francis; 2020

31. Conte M, Eshun-Wilson I, Geng E, Imbert E, Hickey MD, Havlir D, et al. Understanding preferences for HIV care among patients experiencing homelessness or unstable housing: a discrete choice experiment. J Acquir Immune Defic Synd. 2020;85(4):444-9.

32. Miners A, Llewellyn C, Cooper V, Youssef E, Pollard A, Lagarde M, et al. A discrete choice experiment to assess people living with HIV's (PLWHIV's) preferences for GP or HIV clinic appointments. Sex Transm Infect. 2017;93(2):105-11.

33. Albus C, Schmeißer N, Salzberger B, Fätkenheuer G. Preferences regarding medical and psychosocial support in HIV-infected patients. Patient Educ Counsel. 2005;56(1):16-20.

34. Eshun-Wilson I, Mukumbwa-Mwenechanya M, Kim H-Y, Zannolini A, Mwamba CP, Dowdy D, et al. Differentiated care preferences of stable 
patients on antiretroviral therapy in Zambia: a discrete choice experiment. J Acquir Immune Defic Syndr. 2019;81(5):540.

35. Muiruri C, Jazowski SA, Semvua SK, Karia FP, Knettel BA, Zullig LL, et al. Does antiretroviral therapy packaging matter? Perceptions and preferences of antiretroviral therapy packaging for people living with HIV in Northern Tanzania. Patient Prefer Adherence. 2020;14:153.

36. Opuni M, Bishai D, Gray GE, Mclntyre JA, Martinson N. Preferences for characteristics of antiretroviral therapy provision in Johannesburg, South Africa: results of a conjoint analysis. AIDS Behav. 2010;14(4):807-15.

37. Rabkin M, Strauss M, Mantell JE, Mapingure M, Masvawure TB, Lamb MR, et al. Optimizing differentiated treatment models for people living with HIV in urban Zimbabwe: Findings from a mixed methods study. PLoS ONE. 2020;15(1):e0228148.

38. Strauss M, George G, Mantell JE, Mapingure M, Masvawure TB, Lamb MR, et al. Optimizing differentiated HIV treatment models in urban Zimbabwe: assessing patient preferences using a discrete choice experiment. AIDS Behav. 2020;25:1-17.

39. Tanle A, Akwasi K-K, Mariwah S, Kobina E-D, Asiedu SO, Lamptey J. Preferences for antiretroviral therapy services: qualitative evidence from people living with HIV in Ghana. Ghana J Geogr. 2017;9(1):1-16.

40. Zanolini A, Sikombe K, Sikazwe I, Eshun-Wilson I, Somwe P, Bolton Moore C, et al. Understanding preferences for HIV care and treatment in Zambia: Evidence from a discrete choice experiment among patients who have been lost to follow-up. PLoS Med. 2018;15(8):e1002636.

41. Beusterien KM, Dziekan K, Flood E, Harding G, Jordan J. Understanding patient preferences for HIV medications using adaptive conjoint analysis: feasibility assessment. Value Health. 2005;8(4):453-61.

42. Eaton EF, McDavid C, Banasiewicz MK, Mugavero MJ, Knight S. Patient preferences for antiretroviral therapy: effectiveness, quality of life, access and novel delivery methods. Patient Prefer Adherence. 2017;11:1585.

43. Hauber AB, Mohamed AF, Watson ME, Johnson FR, Hernandez JE. Benefits, risk, and uncertainty: preferences of antiretroviral-naïve African Americans for HIV treatments. AIDS Patient Care STDs. 2009;23(1):29-34.

44. Hendriks A, Wijnen B, van Engelen R, Conde R, Evers SM, Gonzalez J, et al. A best-worst scaling in Colombian patients to rank the characteristics of HIV/AIDS treatment. J Med Econ. 2018;21(5):468-73.

45. Miller LG, Huffman HB, Weidmer BA. Hays RD Patient preferences regarding antiretroviral therapy. Int J STD AIDS. 2002;13(9):593-601.

46. Ostermann J, Mühlbacher A, Brown DS, Regier DA, Hobbie A, Weinhold $A$, et al. Heterogeneous patient preferences for modern antiretroviral therapy: results of a discrete choice experiment. Value Health. 2020;23(7):851-61.

47. Sherer RD Jr, Fath MJ, Da Silva BA, Nicolau A-M, Miller NL. The importance of potency and durability in HIV patient antiretroviral therapy preferences: a telephone survey. AIDS Patient Care STDs. 2005;19(12):794-802.

48. Sijstermans E, Cheung KL, Goossens AJ, Conde R, Gonzalez JG, Hiligsmann MJ. A discrete choice experiment to assess patients' preferences for HIV treatment in the urban population in Colombia. J Med Econ. 2020;23:1-7.

49. Yelverton V, Ostermann J, Hobbie A, Madut D, Thielman NJ. A mixed methods approach to understanding antiretroviral treatment preferences: what do patients really want? AIDS Patient Care STDs. 2018:32(9):340-8.

50. Brégigeon-Ronot S, Cheret A, Cabié A, Prazuck T, Volny-Anne A, Ali S, et al. Evaluating patient preference and satisfaction for human immunodeficiency virus therapy in France. Patient Prefer Adherence. 2017;11:1159.
51. José MAF, Garcés PA, López JC, Quirós BD, et al. HIV patients'appraisal of antiretroviral treatment characteristics in Spain. Revista Multidisciplinar del Sida. 2015;3(5):7-20.

52. Lloyd A, Collomb D, Hearn S, Ali S, Mughal FJHM. Patient and physician preferences regarding medications for HIV treatment: P138. HIV Med. 2013;14:55-6.

53. Moyle G. The assessing patients' preferred treatments (APPT-1) study. Int J STD AIDS. 2003;14(1_suppl):34-6.

54. Mühlbacher AC, Stoll M, Mahlich J, Nübling M. Patient preferences for HIV/AIDS therapy—a discrete choice experiment. Heal Econ Rev. 2013;3(1):1-8

55. Beusterien K, Dziekan K, Schrader S, Flood E, Flood R, Shearer A, et al. Patient preferences among third agent HIV medications: a US and German perspective. AIDS Care. 2007;19(8):982-8.

56. Adjetey V, Obiri-Yeboah D, Dornoo B. Differentiated service delivery: a qualitative study of people living with HIV and accessing care in a tertiary facility in Ghana. BMC Health Serv Res. 2019;19(1):1-7.

57. Engelhard EA, Smit C, Kroon FP, Nieuwkerk PT, Reiss P, Brinkman K, et al. A survey of patients' perspectives on outpatient HIV care in the Netherlands. Infect Dis Ther. 2017:6(3):443-52.

58. Hogan TP, Palmer CL. Information preferences and practices among people living with HIV/AIDS: results from a nationwide survey. J Med Libr Assoc. 2005;93(4):431.

59. Kuchukhidze SLL, Pascoe S, Huber A, Nichols B, Fox M, Rosen S. Patient benefits and costs associated with differentiated models of service delivery for HIV treatment in Sub-Saharan Africa. AMBIT Project; 2019. https:// www.heroza.org/wp-content/uploads/2019/09/AMBIT-report-01-patie nt-benefits-and-costs-Sept-03-2019-v1.1-1.pdf. Accessed 21 Jan 2021.

60. Mutasa-Apollo T, Ford N, Wiens M, Socias ME, Negussie E, Wu P, et al. Effect of frequency of clinic visits and medication pick-up on antiretroviral treatment outcomes: a systematic literature review and meta-analysis. J Int AIDS Soc. 2017;20:21647.

61. Ramadhani HO, Muiruri C, Maro VP, Nyombi B, Omondi M, Mushi JB, et al. Patient-initiated repackaging of antiretroviral therapy, viral suppression and drug resistance. AIDS Behav. 2018;22(5):1671-8.

62. World Health Organization. People-centred health care: a policy framework 2007: https://www.who.int/publications/i/item/9789290613176. Accessed 24 Apr 2021

63. de los Rios P, Okoli C, Young B, Allan B, Castellanos E, Brough G, et al. Treatment aspirations and attitudes towards innovative medications among people living with HIV in 25 countries. Popul Med. 2020;2:1-3

64. Garris C, Heidenreich S, Arthurs E. Preceptions of and preferences for oral or long-acting injectable antiretroviral treatment regimens in the United States and Canada. 2019:2-6.

65. Claborn KR, Meier E, Miller MB, Leffingwell TR. A systematic review of treatment fatigue among HIV-infected patients prescribed antiretroviral therapy. Psychol Health Med. 2015;20(3):255-65.

\section{Publisher's Note}

Springer Nature remains neutral with regard to jurisdictional claims in published maps and institutional affiliations. 